\title{
Crucial Role of Mesoscale Convective Systems in the Vertical Mass, Water, and Energy Transports of the South Asian Summer Monsoon
}

\author{
Xingchao Chen, ${ }^{\mathrm{a}, \mathrm{b}}$ L. Ruby Leung, ${ }^{\mathrm{c}}$ ZHe Feng, $^{\mathrm{c}}$ And Fengfei Song ${ }^{\mathrm{c}}$ \\ ${ }^{a}$ Department of Meteorology and Atmospheric Science, The Pennsylvania State University, University Park, Pennsylvania \\ ${ }^{\mathrm{b}}$ Center for Advanced Data Assimilation and Predictability Techniques, The Pennsylvania State University, University Park, \\ Pennsylvania \\ ${ }^{\mathrm{c}}$ Atmospheric Sciences and Global Change, Pacific Northwest National Laboratory, Richland, Washington
}

(Manuscript received 8 February 2021, in final form 30 August 2021)

\begin{abstract}
Convective vertical transport is critical in the monsoonal overturning, but the relative roles of different convective systems are not well understood. This study used a cloud classification and tracking technique to decompose a convection-permitting simulation of the South Asian summer monsoon (SASM) into subregimes of mesoscale convective systems (MCSs), non-MCS deep convection (non-MCS), congestus, and shallow convection/clear sky. Isentropic analysis is adopted to quantify the contributions of different convective systems to the total SASM vertical mass, water, and energy transports. The results underscore the crucial roles of MCSs in the SASM vertical transports. Compared to non-MCSs, the total mass and energy transports by MCSs are at least 1.5 times stronger throughout the troposphere, with a larger contributing fraction from convective updrafts compared to upward motion in stratiform regions. Occurrence frequency of non-MCSs is around 40 times higher than that of MCSs. However, per instantaneous convection features, the vertical transports and net moist static energy (MSE) exported by MCSs are about 70-100 and 58 times stronger than that of nonMCSs. While these differences are dominantly contributed by differences in the per-feature MCS and non-MCS area coverage, MCSs also show stronger transport intensities than non-MCSs over both ocean and land. Oceanic MCSs and nonMCSs show more obvious top-heavy structures than their inland counterparts, which are closely related to the widespread stratiform over ocean. Compared to the monsoon break phase, MCSs occur more frequently ( $\sim 1.6$ times) but their vertical transport intensity slightly weakens (by $\sim 10 \%$ ) during the active phases. These results are useful for understanding the SASM and advancing the energetic framework.
\end{abstract}

KEYWORDS: Convection; Monsoons; Regional models

\section{Introduction}

The South Asian summer monsoon (SASM) is the strongest monsoon system on Earth, contributing $\sim 80 \%$ of the annual precipitation over South Asia (Wang et al. 2017). Its large-scale atmospheric overturning circulation is dominated by a single cross-equatorial Hadley cell, with a planetary-scale ascent over South Asia, and a planetary-scale subsidence over the south Indian Ocean east of Madagascar (Trenberth et al. 2000). In recent years, the atmospheric overturning circulation of the SASM has been interpreted through the lens of the convective quasi-equilibrium (CQE) theory (Emanuel et al. 1994). Within the framework of CQE, the strength of monsoonal overturning is related to the horizontal gradient in the moist entropy supplied to the atmosphere by external sources such as radiation and surface enthalpy fluxes, while the interactions between convection and the large-scale circulation lie at the heart of the monsoon energetics (Neelin and Held 1987; Boos and Kuang 2010; Boos 2015; Ma et al. 2019). As a fast process, convection in the ascending branch of the SASM overturning redistributes mass, water, and energy vertically, limiting large accumulation of convective available potential energy (CAPE) and maintaining a quasi-equilibrium state between convective activity and the large-scale forcings. Hence, the vertical temperature structure of the troposphere above the cloud base nearly

Corresponding author: Xingchao Chen, xzc55@psu.edu follows a moist adiabat (Nie et al. 2010). From a moist entropy budget perspective, convection modulates radiation and surface enthalpy fluxes by the cloud-radiative (Guo et al. 2015) and convection-wind-evaporation (Luo and Stephens 2006) feedbacks in the SASM. In addition, the thermally driven convective overturning imports or exports moist static energy (MSE) into or out of the atmosphere column, leading to a change in the gross moist stability, which further modulates the large-scale monsoonal overturning (Back and Bretherton 2006; Raymond et al. 2009; Boos 2015; Inoue and Back 2015).

The import/export of MSE to the atmosphere column is sensitive to the vertical motion profiles of convection (Back and Bretherton 2006; Inoue and Back 2015). Specifically, convection with a bottom-heavy transport profile leads to a net import of MSE and negative gross moist stability, and thus destabilizes the monsoon system through column moistening. Conversely, convection with a top-heavy transport profile leads to a net export of MSE and positive gross moist stability, and thus stabilizes the monsoon system. Analysis of long-term satellite observations has revealed the complexity of the convective systems occurring during the SASM (e.g., Schumacher and Houze 2003a; Romatschke et al. 2010; Romatschke and Houze 2011; Xu and Zipser 2012; Houze et al. 2015; Virts and Houze 2016). In terms of the vertical depth, the SASM convection can be classified into three categories: deep convection, congestus, and shallow convection, with cloud tops located much higher, around, and well below the melting level, respectively 
(Saikranthi et al. 2014; Bhat and Kumar 2015; Kumar and Bhat 2017). This vertical morphology is consistent with the trimodal characteristics of convection observed over the tropical oceans (Johnson et al. 1999). Furthermore, deep convection in the SASM shows different organizations and horizontal structures (e.g., Romatschke and Houze 2011). Besides isolated deep convection, mesoscale convective systems (MCSs) frequently occur in the SASM; dynamically distinct from non-MCS deep convection, MCSs contribute more than half of the monsoonal precipitation over the South Asia region (Mohr et al. 1999; Houze 2004; Virts and Houze 2016). Convective systems with different vertical and spatial scales also have distinct vertical latent heating and transport profiles (Yanai et al. 1973; Zuluaga et al. 2010; Ahmed et al. 2016).

Our current understanding of the vertical transports associated with different convective systems in the SASM remains incomplete. This is partially due to the lack of in situ observations over the SASM region, limiting our ability to characterize the essential features of different convective systems. Furthermore, simulating convection has been notoriously difficult for global models that rely on cumulus parameterizations, which severely limit our confidence in using global reanalyses to investigate convective activity in the SASM. Feasibility of continental-scale convection-permitting simulations using limited area models has made it possible to study the convective activity in the planetary-scale SASM.

In this study, a convection-permitting regional simulation and isentropic analysis are used to investigate the relative contributions of different convective systems to the SASM overturning. By separating the atmospheric ascents at relatively higher entropy from the descents at relatively lower entropy, isentropic analysis provides a useful framework for investigating the atmospheric overturnings across different spatial scales (e.g., Pauluis et al. 2008; Pauluis and Mrowiec 2013). Going beyond isentropic analysis of the multiscale atmospheric overturnings in the tropics and monsoons (Chen et al. 2018c,b, 2020; Sabin and Pauluis 2020), this study combines the isentropic analysis with a cloud classification and tracking algorithm to examine the relative roles of different convective systems in the SASM overturning. Hence, this study represents an important step toward an improved understanding of the SASM and contributes to advancing the energetic framework by quantifying the role of different convective systems in the import and export of MSE (Biasutti et al. 2018). This study also aims to provide metrics useful for benchmarking the ability of climate models in representing the convective vertical transports of mass, energy, and moisture associated with the SASM overturning.

\section{Experimental setup and methodology}

\section{a. WRF Model setup}

The Weather Research and Forecasting (WRF) Model (Skamarock et al. 2008), version 3.4.1, is used in this study. A model configuration similar to that used in Chen et al. (2018a, hereafter $\mathrm{C} 18$ ) is adopted in this study. In C18, the authors used a 9-km model horizontal grid spacing without any deep convection parameterization to simulate the SASM precipitation. Although the $9-\mathrm{km}$ grid spacing is inadequate for simulating isolated convection, the "gray zone" resolution can capture the primary characteristics of mesoscale systems, so it has been widely used in simulating tropical cyclones and MCSs (e.g., Wang et al. 2015; Chen and Zhang 2019a,b; Chan et al. 2020b; Chen et al. 2021). This study uses a $4.5-\mathrm{km}$ grid spacing in order to better resolve the characteristics of convection in the SASM. The simulation is performed over a single domain that covers most of South Asia with $1554 \times 888$ grid points (the WRF domain is shown in Fig. 2). The model is configured with 45 vertical levels, including 9 vertical levels in the lowest $1 \mathrm{~km}$, and a model top at $20 \mathrm{hPa}$.

Similar to C18, the simulation employs the updated Goddard shortwave scheme (Shi et al. 2010), the GCM version of the Rapid Radiative Transfer Model (RRTMG) longwave radiation scheme (Iacono et al. 2008), the unified Noah land surface physical scheme (Chen and Dudhia 2001), and the new version of the asymmetric convective model (ACM2; Pleim 2007) as the boundary layer scheme. As suggested by C18, the use of the WRF double-moment (WDM) microphysics scheme (Lim and Hong 2010) led to a severe underestimation of stratiform precipitation. Hence, this study uses the Thompson microphysics scheme (Thompson et al. 2008), which leads to a better simulation of the convective/stratiform rainfall fractions (not shown here). The model integrations start from 0000 UTC 20 April 2009 as in C18. Analyses will focus on the boreal summer season from June to August (JJA).

\section{b. Cloud classification and tracking}

A novel process-oriented cloud classification and tracking algorithm is used to identify different types of convective systems in the WRF simulation. The workflow is similar to the procedure of the Flexible Object Tracker (FLEXTRKR; Feng et al. 2018, 2021b), which has been widely used to investigate the observed and simulated convective systems and their largescale environments (e.g., Feng et al. 2016, 2019; Song et al. 2019; Feng et al. 2021a; Hu et al. 2020). Cold cloud systems (CCSs) associated with deep convection are first identified from the WRF hourly outputs following the methodology detailed in Feng et al. (2018). The WRF simulated outgoing longwave radiation is empirically converted to infrared $(11.5 \mu \mathrm{m})$ brightness temperature $\left(T_{b}\right)$ following Yang and Slingo (2001). A CCS is defined by iteratively growing a cold cloud core with the simulated $T_{b}<225 \mathrm{~K}$ outwards to reach $241 \mathrm{~K}$. Each simulated CCS feature is then tracked if the overlapped area is more than $50 \%$ between two successive hourly model outputs. MCS is defined as a large CCS that exceeds $4 \times 10^{4} \mathrm{~km}^{2}$, with the major axis length of its precipitation feature $(\mathrm{PF}) \geq 100 \mathrm{~km}$, the PF area, $P F$ mean rain rate, $P F$ rain-rate skewness, and heavy rain (rain rate $>10 \mathrm{~mm} \mathrm{~h}^{-1}$ ) volume ratio larger than the lifetimedependent thresholds provided in Feng et al. (2021b) and persisting for at least $4 \mathrm{~h}$. CCSs that do not meet the MCS criteria are defined as non-MCS deep convection. We have tested the sensitivity of the algorithm to different MCS size, rainfall parameters, and lifetime thresholds. Because MCSs in the SASM are in general long-lived and intense, the cloud classification and tracking results are not sensitive to small changes in the MCS 
(a) Total Precipitation

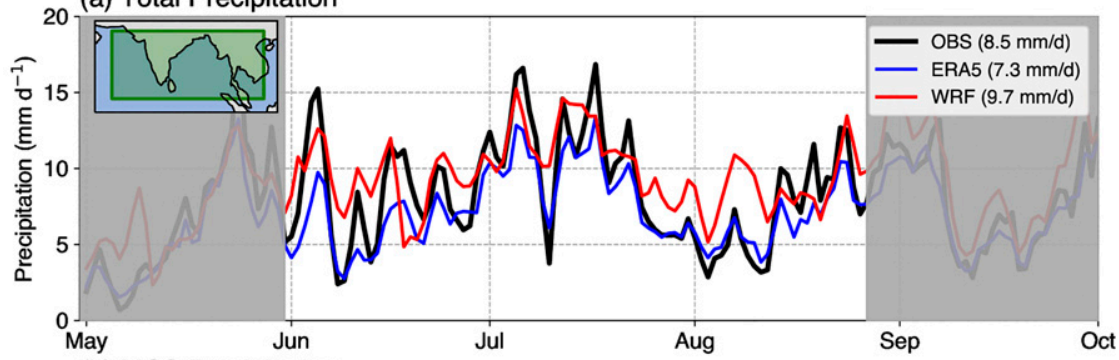

(b) MCS Precipitation

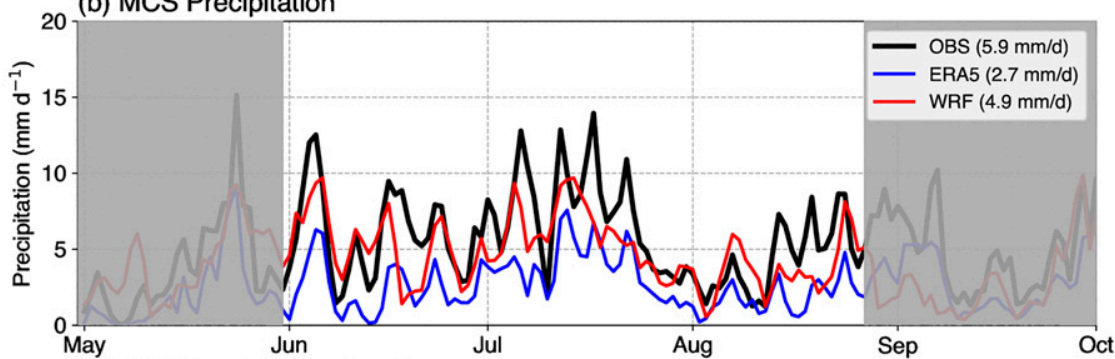

(c) MCS Precipitation Fraction

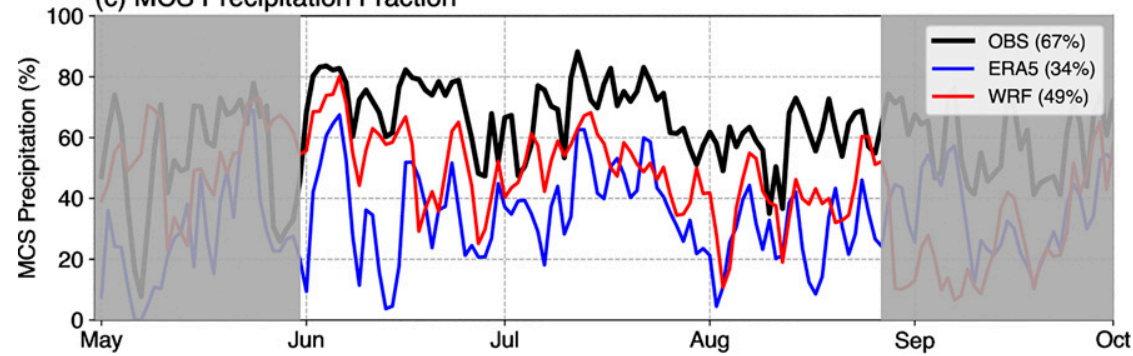

FIG. 1. (a) Temporal evolutions of daily rainfall averaged over South Asia from the IMERG observation (black line), ERA5 (blue line), and the WRF simulation (red line). The JJAaveraged daily rainfall amounts are shown in the upper-right corner of (a). (b),(c) As in (a), but for the MCS precipitation and the precipitation fraction contributed by MCS. The green box in the upper-left corner of (a) shows the South Asian region.

criteria (e.g., changing the lifetime threshold of MCS from 4 to $6 \mathrm{~h}$ produces similar results). Readers can also refer to Feng et al. (2018, 2021b) for a more detailed interpretation of the algorithm. Besides the area occupied by the CCSs, model grid points with nonnegligible precipitation $\left(\geq 0.5 \mathrm{~mm} \mathrm{~h}^{-1}\right)$ and cloud-top $T_{b}<270 \mathrm{~K}$ are defined as the congestus subregime (Wall et al. 2013). The rest of the model grid points are then defined as either the clear-sky or shallow convection subregime (hereafter, shallow + clear). Shallow convection includes both shallow convective clouds and dry shallow convection. In section 3 , we will show that this classification and tracking algorithm can well separate the typical overturning (or vertical transport) of different convective systems in the SASM. However, it should be noted that the model resolution $(4.5 \mathrm{~km})$ used in this study is still inadequate to resolve the detailed dynamics of either congestus or shallow convection. Hence, results related to congestus and shallow convection can only be viewed qualitatively.

\section{c. Comparisons with observations and ERA5 reanalysis}

The NASA global precipitation measurement (GPM) integrated multisatellite retrievals (IMERG) V06B half hourly $0.1^{\circ} \times 0.1^{\circ}$ resolution dataset (Huffman et al. 2019) is used to evaluate the WRF simulated rainfall. IMERG shows considerable improvement over the Tropical Rainfall Measuring Mission (TRMM) Multisatellite Precipitation Analysis (TMPA) dataset in estimating precipitation over the SASM region (e.g., Prakash et al. 2018). The $0.25^{\circ}$ resolution ERA5 reanalysis (Hoffmann et al. 2019) is used here as a reference for the comparisons. Chen et al. (2020) showed ERA5 can better capture the mesoscale atmospheric overturning circulation compared to its predecessor ERA-Interim. Figure 1a shows the temporal evolution of the daily surface rainfall averaged over the South Asia region from IMERG, WRF, and ERA5. The WRF simulation realistically captures the daily evolution of monsoonal precipitation with a similar performance as ERA5, although the WRF simulation overestimates $\left(9.7 \mathrm{~mm} \mathrm{day}^{-1}\right)$ and ERA5 underestimates $\left(7.3 \mathrm{~mm} \mathrm{day}{ }^{-1}\right)$ the JJA-averaged daily rainfall compared to the IMERG observation $\left(8.5 \mathrm{~mm}\right.$ day $\left.{ }^{-1}\right)$. The daily rainfall in the WRF simulation shows a similar spatial pattern as the IMERG observation and the simulation in C18 (not shown here).

To further evaluate the convection-permitting WRF simulation of different convective systems, cloud classification and tracking are also performed on the satellite observations and 

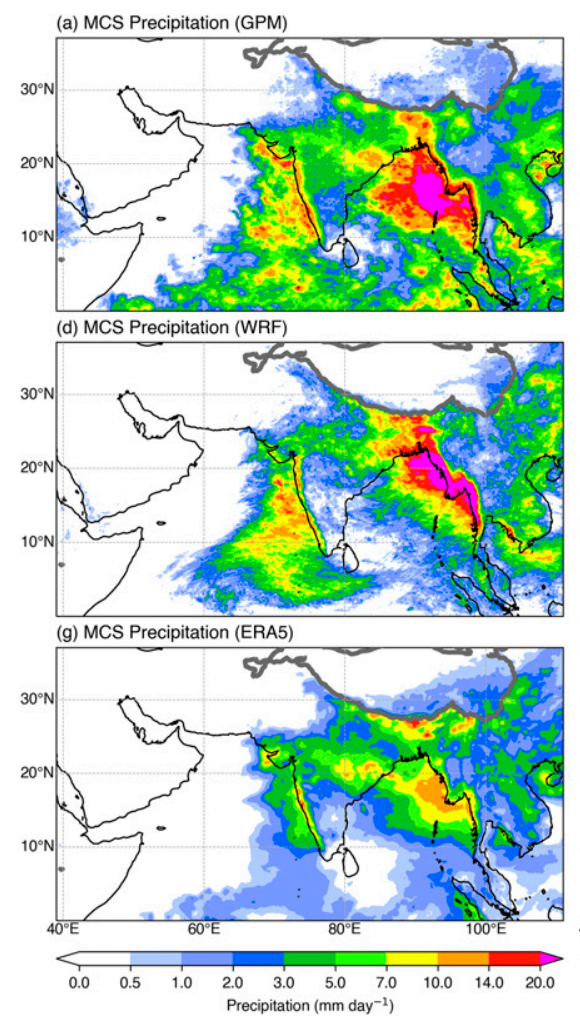

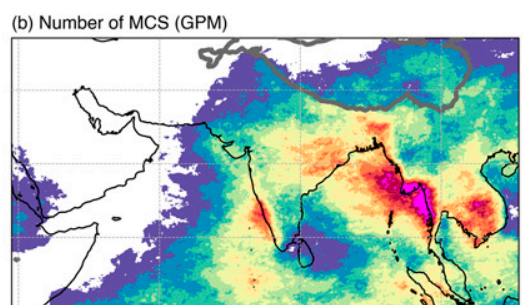

(e) Number of MCS (WRF)
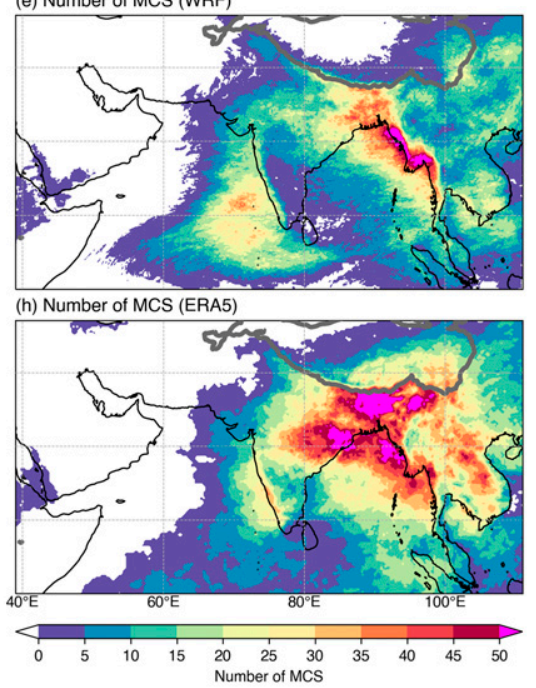

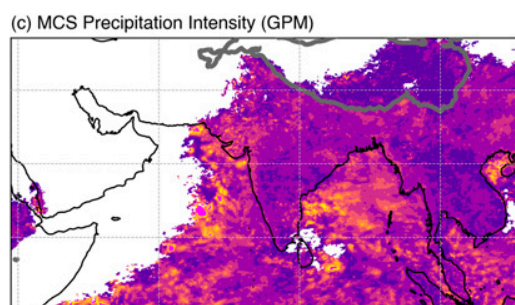

(f) MCS Precipitation Intensity (WRF)

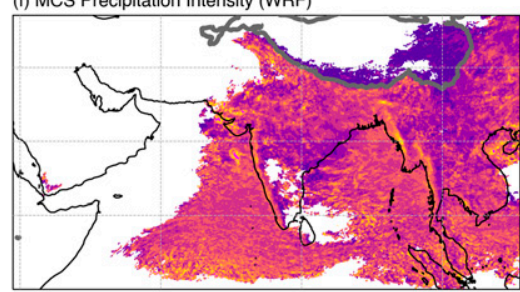

(i) MCS Precipitation Intensity (ERA5)

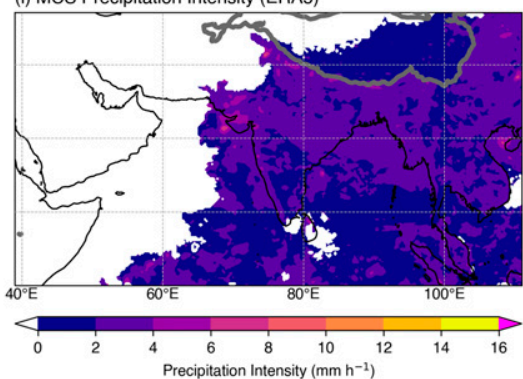

FIG. 2. Spatial distributions of the observed MCS (a) daily precipitation, (b) total number, and (c) mean rain rate from satellite observations averaged over 2009 JJA. (d)-(i) As in (a)-(c), but for the WRF simulation in (d)-(f) and ERA5 reanalysis in (g)-(i). The WRF and ERA5 results have been interpolated to the IMERG reference resolution $(\sim 10 \mathrm{~km})$. In (c), (f), and (i), only regions with number of MCS $>2$ are shown. Thick gray line shows terrain height larger than $3000 \mathrm{~m}$ above sea level.

the ERA5 reanalysis. Satellite observations used here include a global merged geostationary satellite $11.5-\mu \mathrm{m}$ infrared $T_{b}$ dataset produced by the Climate Prediction Center and National Centers for Environmental Prediction (Janowiak et al. 2017) and the IMERG rainfall dataset (Huffman et al. 2019), with a combined spatiotemporal resolution of $10 \mathrm{~km}$ and hourly (Feng et al. 2021b). Considering the ERA5 reanalysis and WRF simulation are at different spatial resolutions, the MCS identification criteria for ERA5 have been adjusted following Feng et al. (2021a). In particular, PF mean rain rate and rain-rate skewness thresholds for ERA5 follow those derived from the $25-\mathrm{km}$ resolution datasets in Feng et al. (2021a) to account for weaker precipitation and reduced spatial variability at coarser resolution.

From the cloud classification, we obtain 2009 JJA non-MCS deep convection daily rainfall rates of $1.3 \mathrm{~mm}^{\text {day }}{ }^{-1}$ for WRF and $0.9 \mathrm{~mm} \mathrm{day}^{-1}$ for ERA5, closely aligning with $1.1 \mathrm{~mm}$ day ${ }^{-1}$ from satellite observations. However, both WRF and ERA5 overestimate the rainfall produced by congestus, with average daily rainfall amounts of $1.2,3.1,2.5 \mathrm{~mm} \mathrm{day}^{-1}$ in JJA in the satellite observations, WRF, and ERA5, respectively. The observed variations of daily rainfall over South Asia (Fig. 1a) can be largely explained by the variability of MCS precipitation (Fig. 1b). MCSs contribute to around $67 \%$ of the total rainfall over South Asia (Fig. 1c), with a JJA-averaged daily rainfall amount around $5.9 \mathrm{~mm} \mathrm{day}^{-1}$. The ERA5 reanalysis severely underestimates the MCS daily rainfall (2.7 $\mathrm{mm}_{\text {day }}{ }^{-1}$; Fig. 1b), only accounting for $34 \%$ to the total monsoonal precipitation (Fig. 1c). Although the WRF simulation shows similar underestimation of the MCS rainfall, the biases are greatly reduced ( $4.9 \mathrm{~mm}$ day $^{-1}$ and $49 \%$, respectively; Figs. 1b,c). One may notice that the WRF simulation considerably underproduces MCS precipitation in September (Figs. 1b,c). This is because WRF simulated two tropical cyclones that were MCSs in the satellite observations over the Bay of Bengal. Since the analysis will focus on the JJA period, this model bias in September would not influence the results shown in this paper.

WRF simulation also better captures the spatial distributions of the MCS daily precipitation, total number, and mean rain rate (Fig. 2). The mean MCS rain rates in Fig. 2 are only calculated over grid points with more than two MCS samples to avoid sampling errors. In particular, the WRF simulation captures the two regions with enhanced MCS activity from observations over the Western Ghats and the west coast of Myanmar (Figs. 2a,b,d,e). Strong monsoonal precipitation over these two regions (not shown) is mostly contributed by MCSs. In contrast, ERA5 considerably overestimates the MCS number and underestimates MCS rainfall amount over eastern India and Bangladesh (Figs. 2g,h), while the mean MCS rain rate is significantly weaker (Fig. 2i). It should be noted that, although the WRF simulation is better than the coarse-resolution 

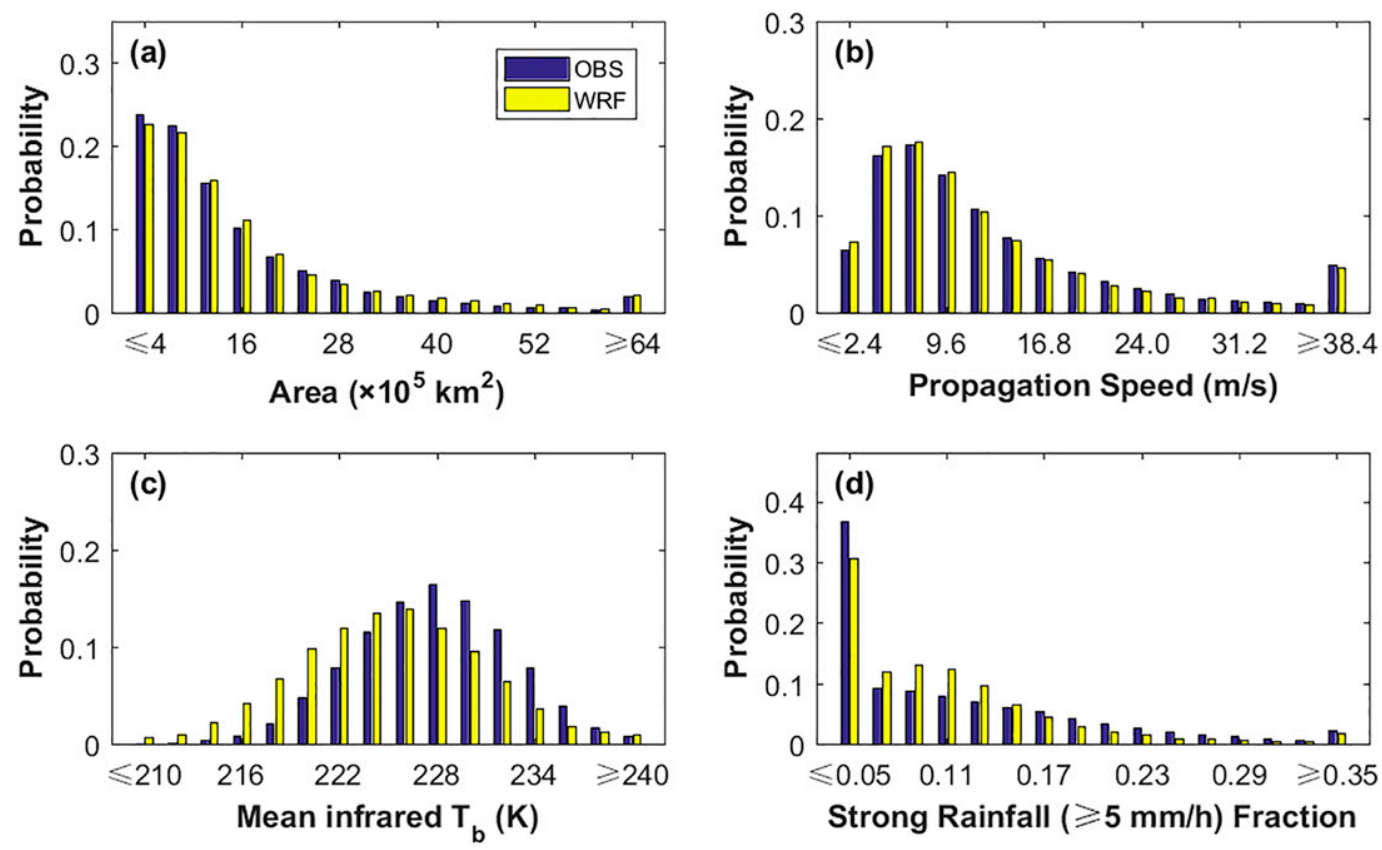

FIG. 3. Probability distributions of the MCS (a) area, (b) propagation speed, (c) mean infrared brightness temperature, and (d) strong rainfall fraction from satellite observations and the WRF simulation.

ERA5 in capturing the SASM MCSs, it still underestimates the number and overestimates the rainfall intensity of MCSs when compared to satellite observations.

The MCS area, propagation speed, mean infrared brightness temperature, and strong rainfall $\left(\geq 5 \mathrm{~mm} \mathrm{~h}^{-1}\right)$ fraction in the WRF simulation are further compared with the satellite observations. The vertical transport in the simulated MCSs could be sensitive to these metrics (e.g., Senior et al. 2021). Overall, the WRF simulation realistically captures the area and propagation speed of MCSs (Figs. 3a,b). The propagation speed is calculated using the cold cloud shield centroid location differences between two model output times. It reflects the movement of the upper-level cold clouds, but is also influenced by the changes in the shape of cold clouds. As a result, the calculated propagation speed may be slightly faster than the visually estimated propagation speed of the MCS features.

The WRF simulation slightly underestimates the MCS mean brightness temperature, with the simulated kernel of the probability distribution $\sim 2 \mathrm{~K}$ colder than the observed one (Fig. 3c). It reflects that the WRF simulation slightly overestimates the depth of the SASM MCSs, which is likely related to overly strong and wide convective updrafts with the $4.5-\mathrm{km}$ grid spacing (Prein et al. 2021). The probability distributions of strong rainfall fraction from the satellite observations and WRF simulation are similar to each other, but noticeable differences can be found (Fig. 3d). The WRF simulation underestimates the probability of MCSs with small $(\leq 0.05)$ and large $(\geq 0.17)$ strong rainfall fractions but overestimates the probability of MCSs with medium $(>0.05$ and $<0.17)$ strong rainfall fractions. The differences reflect the model biases in simulating MCSs' convective/stratiform rainfall fractions, which are long-standing biases in convection-permitting simulations (Hagos et al. 2014; Varble et al. 2014; Fan et al. 2017; Han et al. 2019).

In summary, although unavoidable model biases exist, the convection-permitting WRF simulation provides a useful dataset for studying the SASM convection. The potential impacts of the WRF Model biases on the results will be discussed in section 5 .

\section{d. Isentropic analysis}

An isentropic analysis technique is used in this study to investigate the vertical mass, water, and energy transports associated with different convective systems in the SASM. The isentropic analysis sorts the vertical transports in terms of the equivalent potential temperature $\left(\theta_{e}\right)$ of air parcels and computes the atmospheric overturning in the isentropic coordinates of $\theta_{e}$ and height (Pauluis and Mrowiec 2013). The isentropic distribution of the vertical mass transport on a given isentropic slice is defined as (Chen et al. 2020):

$$
\begin{aligned}
\langle\rho W\rangle\left(z, \theta_{e 0}\right)= & \frac{1}{P} \int_{0}^{P} \int_{0}^{L_{y}} \int_{0}^{L_{x}} \rho W(x, y, z, t) \delta\left[\theta_{e 0}\right. \\
& \left.-\theta_{e}(x, y, z, t)\right] d x d y d t
\end{aligned}
$$

Here, $z$ is the height above the mean sea level (MSL) and $t$ is the model integration time; $W$ is the vertical velocity, and $\rho$ is the mass per unit volume. The terms $L_{x}$ and $L_{y}$ are the spatial extent of the averaging domain; $P$ is the time period over which the averaging is performed. Here, $\theta_{e 0}$ is the frozen equivalent potential temperature as defined in Pauluis [2016, Eq. (2)]. The frozen equivalent potential temperature considers the latent heating associated with freezing processes, so it is typically larger than the $\theta_{e}$ over liquid water (Emanuel 1994) and can 
better capture the convective overturning above the melting level (Chen et al. 2018c). The $\delta$ is a Dirac function that is equal to $1 / \Delta \theta_{e}$ for $\theta_{e}$ between $\theta_{e 0}-0.5 \Delta \theta_{e}$ and $\theta_{e 0}+0.5 \Delta \theta_{e}$ and 0 elsewhere. The $\Delta \theta_{e}$ used here equals to $1 \mathrm{~K}$. In practice, the integral in (1) amounts to summing the vertical mass transports over the averaging domain at each constant height in finite $\theta_{e}$ bins on an interval of width $\Delta \theta_{e}$. Compared with the traditional Eulerian analysis, the isentropic analysis is a more efficient methodology to separate the vertical transports at different entropies, which emphasizes the fact that the atmospheric overturnings across different scales are all due to the combinations of ascending warm moist air parcels at high entropy and compensated descending colder drier air parcels at low entropy (e.g., Pauluis et al. 2008; Mrowiec et al. 2015, 2016; Slawinska et al. 2016; Fang et al. 2017; Wu et al. 2019; Chen et al. 2020).

Another advantage of the isentropic analysis is its efficiency in characterizing the upward and downward mass, water, and energy transports associated with different convective systems with the two-stream approximation (Pauluis and Mrowiec 2013; Chen et al. 2018b). The upward $M^{+}$and downward $M^{-}$ mass transports are defined as

$$
\begin{aligned}
& M^{+}(z, t)=\int_{-\infty}^{\infty}\langle\rho W\rangle H(\langle\rho W\rangle) d \theta_{e}, \quad \text { and } \\
& M^{-}(z, t)=\int_{-\infty}^{\infty}\langle\rho W\rangle H(-\langle\rho W\rangle) d \theta_{e},
\end{aligned}
$$

where $H$ is a Heaviside step function (value is zero for negative arguments and one for positive arguments). Similarly, the upward and downward water $\left(\mathrm{WT}^{+}\right.$and $\left.\mathrm{WT}^{-}\right)$and energy $\left(\mathrm{EG}^{+}\right.$ and $\mathrm{EG}^{-}$) transports can be calculated as follows:

$$
\begin{aligned}
& \mathrm{WT}^{+}(z, t)=\int_{-\infty}^{\infty}\langle\rho W \times q\rangle H(\langle\rho W\rangle) d \theta_{e}, \\
& \mathrm{WT}^{-}(z, t)=\int_{-\infty}^{\infty}\langle\rho W \times q\rangle H(-\langle\rho W\rangle) d \theta_{e}, \\
& \mathrm{EG}^{+}(z, t)=\int_{-\infty}^{\infty}\langle\rho W \times \mathrm{MSE}\rangle H(\langle\rho W\rangle) d \theta_{e}, \quad \text { and } \\
& \mathrm{EG}^{-}(z, t)=\int_{-\infty}^{\infty}\langle\rho W \times \mathrm{MSE}\rangle H(-\langle\rho W\rangle) d \theta_{e},
\end{aligned}
$$

where $q$ is specific humidity. MSE $=C_{p} T+g z+L_{v} q$ is the moist static energy, with the specific heat capacity of dry air $C_{p}$, temperature $T$, gravitational acceleration $g$, and the latent heat of vaporization $L_{v}$. The isentropic analysis is performed for each convective subregime (i.e., MCS, non-MCS deep convection, congestus, shallow + clear) in the WRF simulation and averaged over 2009 JJA. Model grid points with topography higher than $3000 \mathrm{~m}$ are excluded in the isentropic analysis.

\section{Roles of different convective systems in the SASM overturning}

Figure 4 shows the isentropic distributions of the WRF simulated instantaneous vertical mass transports summing over the MCS, non-MCS deep convection, congestus, and shallow + clear

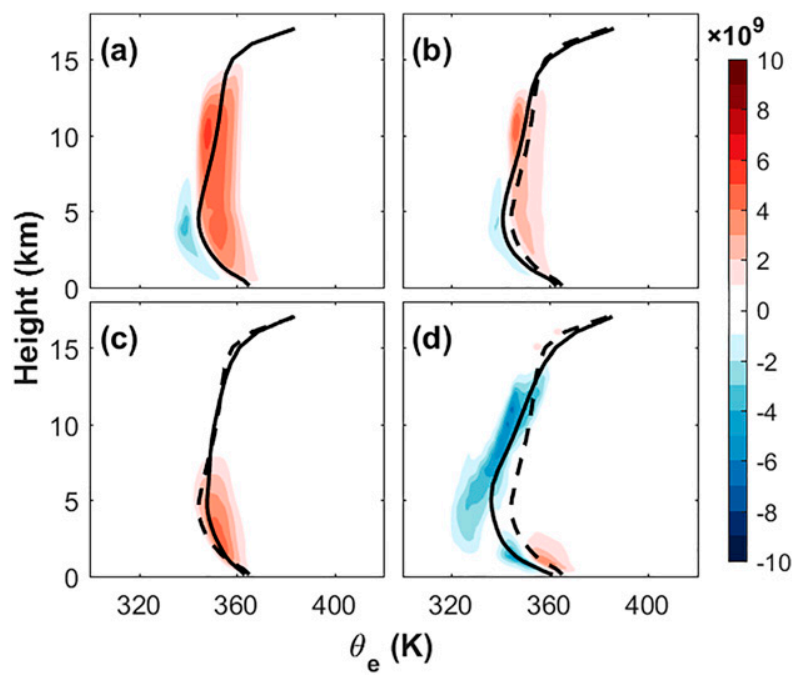

FIG. 4. Isentropic distributions of the WRF simulated vertical mass transports $\left(\mathrm{kg} \mathrm{s}^{-1} \mathrm{~K}^{-1}\right)$ associated with (a) MCS, (b) non-MCS deep convection, (c) congestus, and (d) shallow + clear averaged over 2009 JJA. The black solid lines show the horizontal-mean profiles of equivalent potential temperature averaged over different convective subregimes. The black dashed lines in (b)-(d) are the same as the black solid line in (a).

subregimes averaged over JJA 2009 [Eq. (1)]. The black solid lines represent the horizontal-mean $\theta_{e}$ profiles averaged over different convective subregimes. The MCS overturning circulation is dominated by a strong and deep upward mass transport at high $\theta_{e}$ values $(\sim 350-365 \mathrm{~K}$, shown by the warm colors in Fig. 4a), which corresponds to the warm moist updrafts in the MCS clouds. The $\theta_{e}$ value of the upward mass drops from the surface to the melting level (at $\sim 6 \mathrm{~km}$ ), which is mainly due to the entrainment of environmental drier air. Above the melting level, the MCS upward mass is almost vertical in the $\theta_{e}$ coordinate with little change of its $\theta_{e}$ value, reflecting the reduced dilution by entrainment above the freezing level. The mean $\theta_{e}$ value of the upward mass is higher than the horizontal-mean $\theta_{e}$ in the lower troposphere but similar to the horizontal-mean $\theta_{e}$ above the melting level. The MCS upward mass transport intensity peaks at around $10 \mathrm{~km}$. Besides the deep upward mass transport, a shallow and weak downward mass transport can also be found in the MCS subregime (shown by the cold colors in Fig. 4a). The downward mass transport mostly occurs below the melting level, with $\theta_{e}$ values lower than the horizontalmean $\theta_{e}$ profile, likely associated with the mesoscale downdraft in the stratiform rain region of MCSs (Houze 2004; Schumacher et al. 2015). In addition, the $\theta_{e}$ values of the downward mass increase from the melting level to the surface, which corresponds to the mixing between the subsiding air and the detrained high-entropy air from the MCS updrafts.

Non-MCS deep convection (Fig. 4b) shows a similar overturning structure with MCS, which includes a deep upward mass transport at high $\theta_{e}$ values and a shallow downward mass transport at low $\theta_{e}$ values. However, the total air mass vertically transported by non-MCS deep convection during the SASM is significantly less than $(\sim 50 \%)$ that transported by MCS. 
Their relative contributions to the total SASM overturning will be quantitatively compared later in this section using the twostream approximation. In the lower and middle troposphere, the horizontal-mean $\theta_{e}$ profile averaged over the MCS subregime is around $3 \mathrm{~K}$ warmer than that averaged over the nonMCS deep convection subregime (Figs. 4a,b). This may imply that moister and warmer environment is required in the lower troposphere for MCS initiation and/or such environment may explain MCS's stronger diabatic heating effect compared to non-MCS deep convection.

Different from MCS and non-MCS deep convection, the congestus subregime shows an upward mass transport intensity peaks at around $3.5 \mathrm{~km}$ without any noticeable downward mass transport (Fig. 4c). Figure 4d shows the atmospheric overturning over the shallow + clear subregime. Two distinct components can be found in this subregime: a strong downward mass transport from the upper to the lower troposphere occurring at $\theta_{e}$ values close to the horizontal-mean $\theta_{e}$ profile, and a shallow atmospheric overturning at high $\theta_{e}$ values below $3 \mathrm{~km}$. The downward mass transport in the troposphere corresponds to the subsidence occurring in the clear-sky regions, with $\theta_{e}$ values of the downward mass reducing from the upper to the lower troposphere due to radiative cooling effects. The overturning in the lower troposphere, on the other hand, is associated with shallow convection in the SASM. Without strong latent heating, the horizontal-mean profile of $\theta_{e}$ over the shallow + clear subregime is around $10 \mathrm{~K}$ colder than that in the MCS subregime in the lower and middle troposphere (Fig. 4d).

To understand the asymmetric structures of MCS and nonMCS vertical mass transports (Fig. 4a vs Fig. 4b), their atmospheric overturnings are further separated into the strong $\left(\geq 5 \mathrm{~mm} \mathrm{~h}^{-1}\right)$ and weak $\left(<5 \mathrm{~mm} \mathrm{~h}^{-1}\right)$ precipitation subregions. Previous studies have shown that $5 \mathrm{~mm} \mathrm{~h}^{-1}$ can be used as an approximate criterion to separate convective and stratiform precipitation (e.g., Tokay and Short 1996). The rain-rate criterion successfully separates the overturnings of MCS and nonMCS deep convection into two distinct modes (Fig. 5). A deep upward mass transport that connects the surface with the upper troposphere can be found in the strong precipitation subregions (Figs. 5a,b). This upward mass transport corresponds to the strong convective updrafts in the CCSs. Downward mass transport associated with strong precipitation in the strong precipitation subregion is largely offset by the convective upward transports at similar $\theta_{e}$ values. Hence, no distinct downward mass transport can be found over the subregion. In the weak precipitation subregion, an upward mass transport can be found above the melting level, while a downward mass transport can be found below the melting level (Figs. 5c,d). This feature is consistent with the vertical velocity profile of stratiform precipitation (e.g., Schumacher et al. 2015). The horizontalmean $\theta_{e}$ profile in the strong (convective) precipitation subregion is warmer than that in the weak (stratiform) precipitation subregion, especially in the lower troposphere. It reflects that the convective subregion has warmer temperature and/or higher moisture content than the stratiform subregion. The total upward mass transport in the MCS convective subregion (Fig. 5a) is considerably stronger and deeper than that in the non-MCS

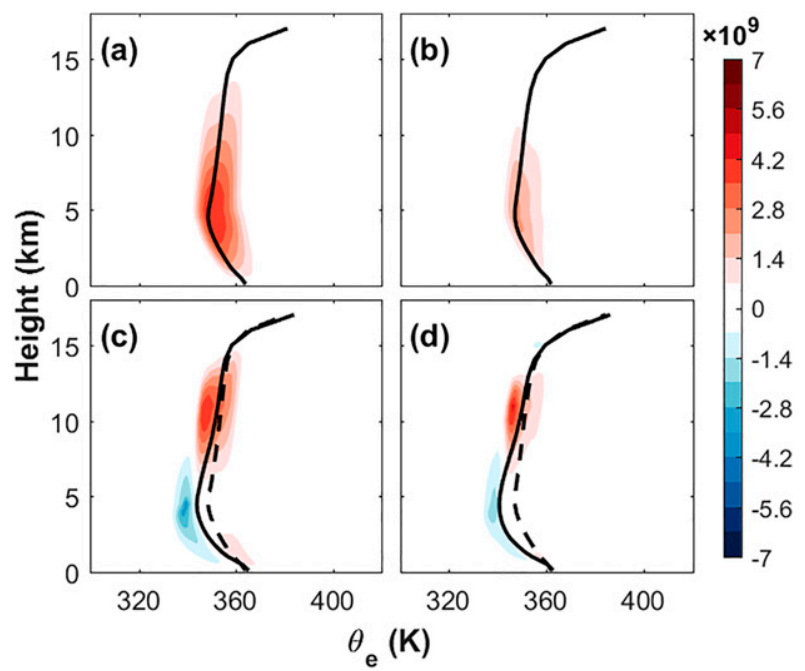

FIG. 5. Isentropic distributions of vertical mass transports ( $\mathrm{kg} \mathrm{s}^{-1} \mathrm{~K}^{-1}$ ) summing over (a) MCS convective, (b) non-MCS convective, (c) MCS stratiform, and (d) non-MCS stratiform subregions. The black solid lines show the horizontal-mean profiles of equivalent potential temperature. The black dashed lines in (c) and (d) are the same as the black solid line in (a) and (b).

convective subregion (Fig. 5b). This difference reflects a larger convective contributing fraction in the MCS overturning, which will be further discussed later in this section.

The relative roles of different convective systems in the vertical mass, water, and energy transports during the SASM are examined using the two-stream approximation (Fig. 6). The total upward mass transport of the SASM shows a doublepeak structure (black line in the right panel of Fig. 6a), with a primary peak at $3.5 \mathrm{~km}$ and a secondary peak at $10 \mathrm{~km}$. This vertical feature is consistent with the analysis in Chen et al. (2018c), which indicated that the lower peak is mainly contributed by the convective-scale overturning circulations and the upper peak is closely related to the meso- to synoptic-scale overturning circulations. The upward mass transport associated with shallow convection is mostly concentrated below $2.5 \mathrm{~km}$. The WRF simulation shows that MCS and congestus contribute most at $42 \%$ and $36 \%$, respectively, to the total upward mass transport peak at $3.5 \mathrm{~km}$. The contribution from non-MCS deep convection in the lower troposphere is much smaller $(\sim 17 \%$ at $3.5 \mathrm{~km})$. However, one should note that the contribution from congestus is very likely to be overestimated since WRF overproduces the total precipitation of congestus by a factor of 2.6. In addition, WRF also underproduces the total precipitation of MCS ( $\sim 83 \%$ of the observed value). Hence, MCS might play an even more crucial role than congestus in the upward mass transport in the lower troposphere. MCS becomes more dominant in the upper troposphere and contributes $\sim 63 \%$ of the total SASM upward mass transport at $10 \mathrm{~km}$ in the WRF simulation. The contribution from non-MCS deep convection at the same altitude is $\sim 36 \%$. In general, the upward mass transport associated with MCS is at least 1.5 times stronger than that of non-MCS deep convection throughout the troposphere. 

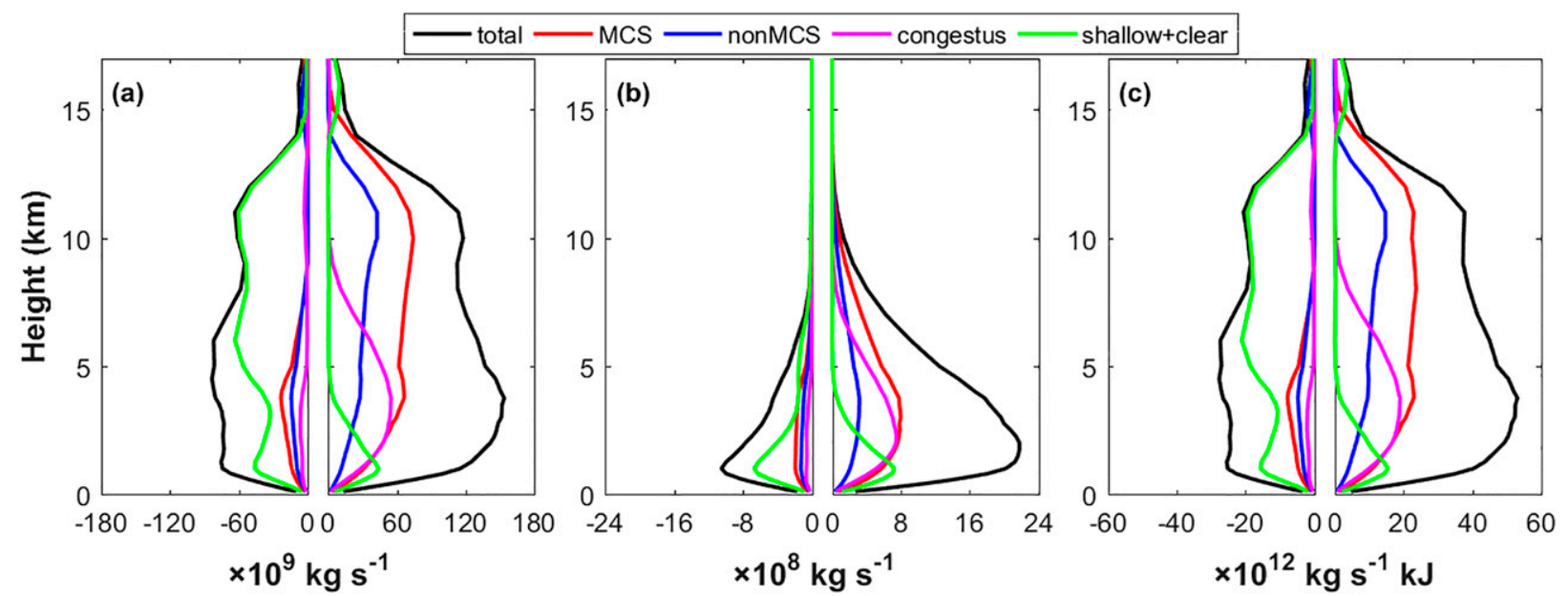

FIG. 6. (a) Vertical distributions of the downward (left) and upward (right) mass transports associated with the SASM (total) and the different convective systems. (b),(c) As in (a), but for vertical water and energy transports, respectively.

In addition, the MCS upward mass transport is strong from the lower $(\sim 3.5 \mathrm{~km})$ to upper $(\sim 10 \mathrm{~km})$ troposphere. However, the non-MCS upward mass transport shows a prominent upper-tropospheric peak at $10 \mathrm{~km}$. The uppertropospheric downward mass transport during the SASM (left panel in Fig. 6a) is mainly contributed by the clear-sky descent. Shallow convection plays an important role in the total downward mass transport below $2.5 \mathrm{~km}$. Meanwhile, the contributions from congestus, MCS, and non-MCS deep convection to the total downward mass transport are relatively smaller.

Because moisture is mostly concentrated in the lower troposphere, both the total upward and downward water transports show bottom-heavy structures (Fig. 6b). The total upward water transport peaks at around $2 \mathrm{~km}$ during the SASM, with the MCS, non-MCS deep convection, congestus, and shallow convection overturnings contributing about $35 \%, 13 \%, 34 \%$, and $18 \%$ at this altitude. Again, the contributing percentage from congestus may be overestimated since WRF considerably overproduces the total precipitation of congestus and slightly underproduces the total precipitation of MCS. Taking the model biases into account, MCS should play a much more important role than congestus in upward water transport in the lower troposphere. MCS dominates the upward water transport in the upper troposphere, with contributing percentages above $60 \%$ at all vertical levels above $8 \mathrm{~km}$. The total downward water transport peaks at around $1 \mathrm{~km}$, which is mostly contributed by shallow convection. Figure $6 \mathrm{c}$ shows the vertical energy transports associated with different convective systems. The vertical structure of energy transports is similar to that of mass transports. Overall, Fig. 6 shows that the total upward mass/water/energy transports are stronger than the total downward mass/water/energy transports during the SASM (black lines in Fig. 6). Because shallow convection shows an approximate symmetric upward and downward transport structure, the net upward mass, water, and energy transports are mainly contributed by the overturnings associated with MCS, non-MCS deep convection, and congestus. MCS plays a crucial role in the vertical mass, water, and energy transports during the SASM.

An MCS occupies a much larger area than a non-MCS deep convection. More importantly, MCSs contain larger convective areas with wider and stronger updrafts, and broader stratiform regions of mesoscale ascent in the upper troposphere. Hence, the per-feature mass, water, and energy transports associated with MCS and non-MCS deep convection are further compared. The numbers of JJA-averaged instantaneous MCS and non-MCS feature within the analysis domain are 9.5 and 376.8. Here, the per-feature transport is defined as the instantaneous total transport summed over each subregime divided by the instantaneous feature number in the subregime. Hence, the vertical structure of the per-feature transports (Fig. 7) is the same as that of the total transports (Fig. 6). However, the per-feature upward mass/water/energy transports associated with an individual MCS is on average around 70-100 times stronger than that of a non-MCS deep convection, mainly due to the larger area of MCSs. Figure 7 also shows the per-feature convective and stratiform transports for the MCS and nonMCS deep convection. The downward mass, water, and energy transports are mainly contributed by the stratiform downdrafts. On the other hand, the lower-tropospheric upward mass/water/energy transports are predominately produced by the convective updrafts. One major difference between the MCS and non-MCS deep convection is that the uppertropospheric upward mass and energy transports in non-MCS deep convection is mainly contributed by the stratiform ascents, which lead to a prominent top-heavy structure (Figs. 7d,f). However, convective updrafts account for a larger fraction of the MCS overturning and greatly ( $\sim 38 \%)$ contribute to the upper-tropospheric upward mass and energy transports (Figs. 7a,c).

In addition, the column-integrated vertical MSE advections $[\langle-\omega(\partial \mathrm{MSE} / \partial p)\rangle]$ per MCS and non-MCS deep convection feature are calculated based on the isentropic averaged mass flux shown in Fig. 7. Quantifying the column integrated vertical MSE advections associated with deep convection is important 


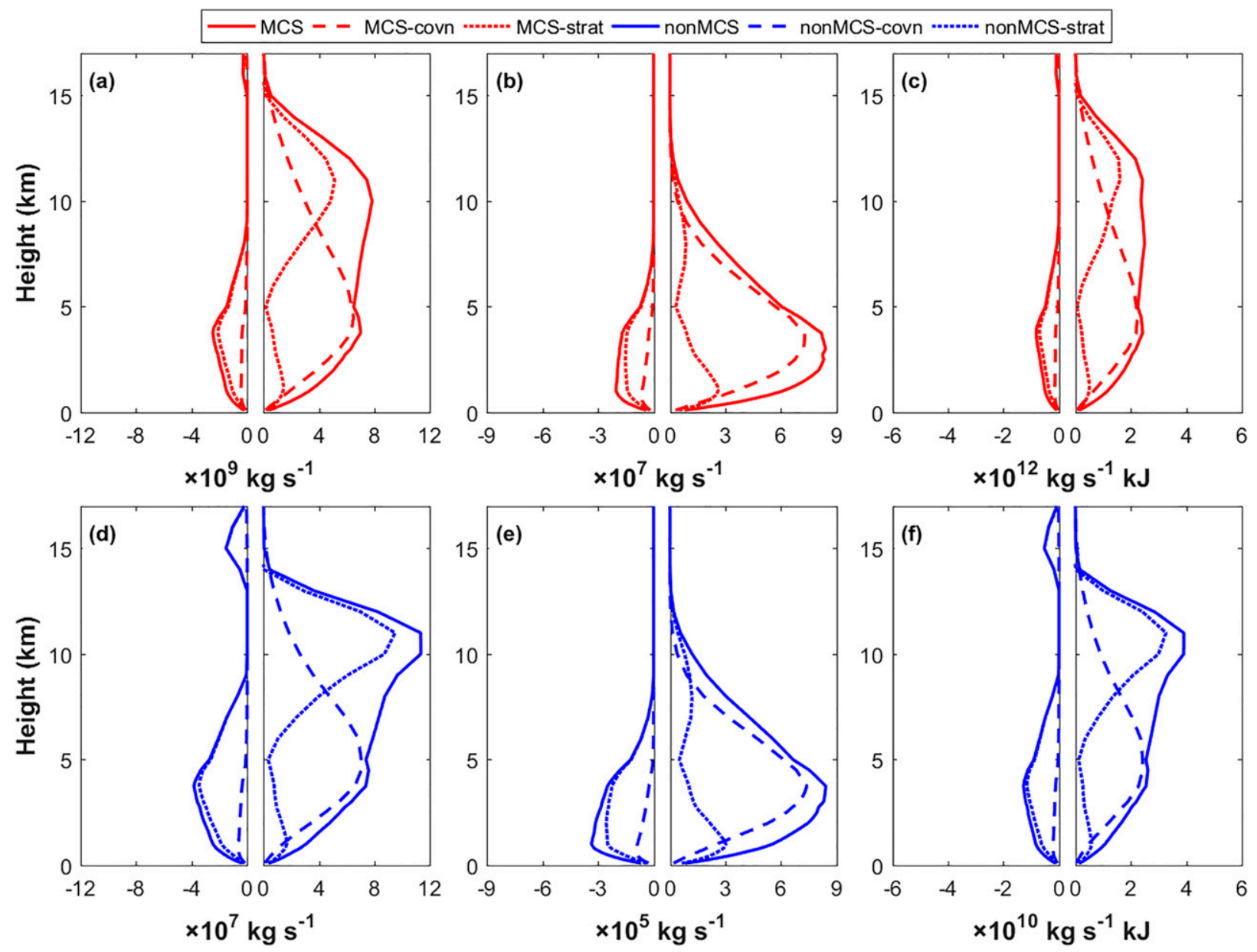

FIG. 7. (a) Vertical distributions of the per-feature MCS (solid line), MCS convective (dashed line), and MCS stratiform (dotted line) downward (left) and upward (right) mass transports. (d) As in (a), but for non-MCS deep convection. (b), (e) As in (a) and (d), but for vertical water transports. (c),(f) As in (a) and (d), but for vertical energy transports. Note that the transport magnitudes of the axes are different between the first and second rows.

for understanding the roles of deep convection in the SASM energetics. The column integrated vertical MSE advection is comparable to the gross moist stability, which can be used to estimate the net MSE export/import produced by convective overturning (Back and Bretherton 2006). A positive column integrated vertical MSE advection reflects convection imports MSE, and a negative value represents convection exports MSE to the atmosphere column. Both MCS and non-MCS deep convection lead to net MSE exports during the SASM, while the per-feature MSE export produced by MCS $(-3.03 \times$ $10^{13} \mathrm{~W}$ ) is about 58 times stronger than that of non-MCS deep convection $\left(-5.16 \times 10^{11} \mathrm{~W}\right)$. The intensity of MCS MSE export $\left(-315 \mathrm{~W} \mathrm{~m}^{-2}\right)$ is also slightly stronger than that of nonMCS deep convection $\left(-294 \mathrm{~W} \mathrm{~m}^{-2}\right)$. The low-level (below the melting level) integrated vertical MSE advections are calculated in order to further understand the MSE imports produced by MCS and non-MCS deep convection in the lower troposphere. The result indicates that, in the lower troposphere, MCS imports much more MSE $\left(1.67 \times 10^{13} \mathrm{~W}\right)$ per feature into the atmosphere compared to non-MCS deep convection $\left(0.17 \times 10^{11} \mathrm{~W}\right)$. It is consistent with the stronger and much wider convective updrafts and broader stratiform ascent within the MCS subregime (Fig. 7a).

The spatial distributions of the lower-tropospheric $(1.5 \mathrm{~km})$ upward mass transports associated with different convective systems are shown in Figs. 8a-8d. MCS, non-MCS deep convection, and congestus show a similar spatial pattern (Figs. 8a-c), with two centers over the Western Ghats and the west coast of Myanmar. These two convective centers also correspond to the rainfall maxima during the SASM. Shallow convection mostly occurs over the inland region, with a maximum over the Middle East where the surface condition is warm and dry. At the same time, another shallow convection center can be found over the Arabian Sea, which is likely induced by the enhanced westerly low-level winds and surface evaporation during the SASM (Fig. 8d). Almost no upward mass transport can be found over the congestus and shallow + clear subregimes in the upper-troposphere (Figs. 8g,h). However, the upward mass transport associated with MCS and nonMCS deep convection increases from the lower to the upper 


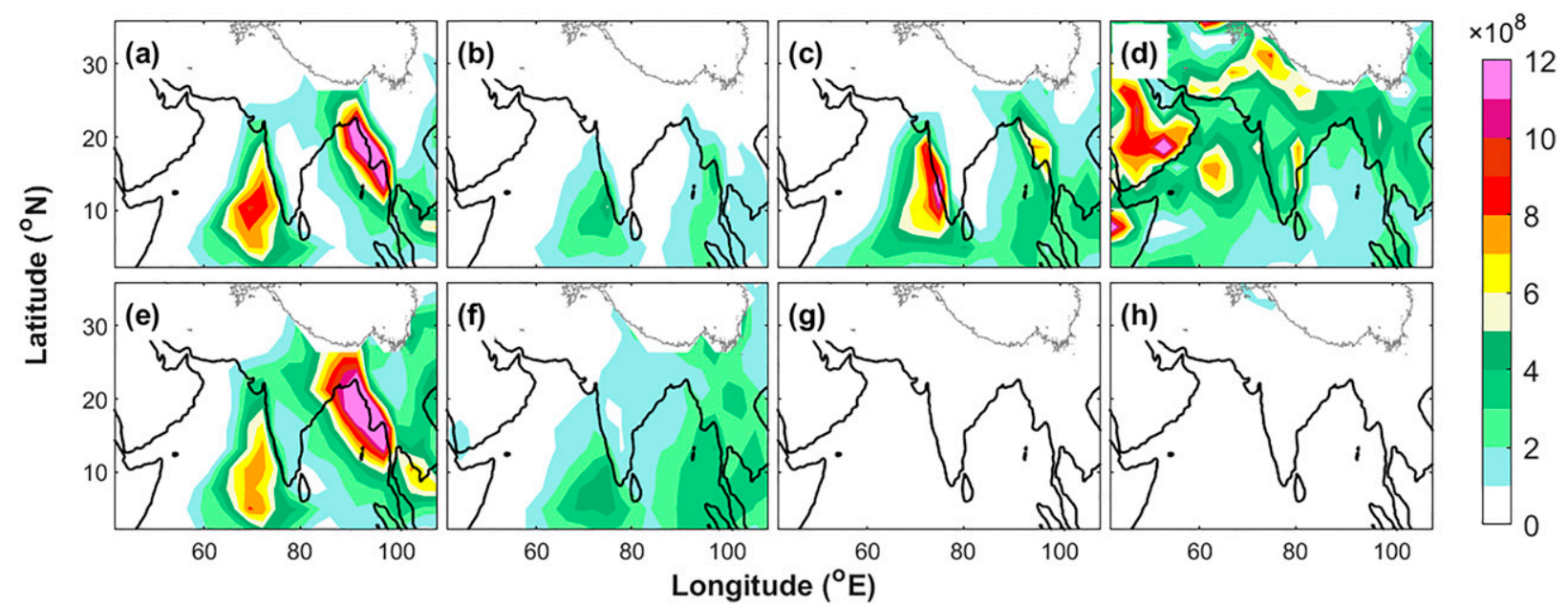

FIG. 8. Isentropic upward mass transport $\left(\mathrm{kg} \mathrm{s}^{-1}\right)$ associated with (a) MCS, (b) non-MCS deep convection, (c) congestus, and (d) shallow convection at 1.5-km altitude averaged over 2019 JJA. (e)-(h) As in (a)-(d), but for 11-km altitude. Coastlines are shown by the black lines and topography higher than $3000 \mathrm{~m}$ is shown by the gray contours.

troposphere (Figs. 8e,f), which is consistent with the vertical structure shown in Fig. 6a. The upward mass transport associated with MCS is stronger than that associated with non-MCS deep convection at both altitudes, with the ratios of 2.7 and 1.7 between the MCS and non-MCS total upward mass transports at 1.5 and $11 \mathrm{~km}$, respectively.

Past observation studies have pointed out the distinct characteristics of offshore and inland deep convection during the SASM (e.g., Romatschke et al. 2010; Romatschke and Houze 2011; Virts and Houze 2016). In general, large convective systems with broad stratiform region are most widespread over ocean, while smaller but deeper convection frequently occurs over land. The larger stratiform fraction in deep convection over ocean may form due to the warm, moist boundary layer with small diurnal variability and/or the near-moist adiabatic stratification of the free atmosphere (Schumacher and Houze 2003b). The oceanic and inland vertical mass, water, and energy transports associated with MCSs and non-MCSs are further compared in Fig. 9. Results show that MCSs have larger contributions to the total vertical mass, water, and energy transports than non-MCSs over both ocean and land (Figs. 9a-c). In addition, the MCS total upward mass/energy transports over ocean are significantly stronger than that over land (Figs. 9a,c). The results are consistent with Figs. 8a,e, which indicate that MCS upward mass transport frequently occurs over ocean. On the other hand, the non-MCS total upward mass and energy transports over ocean are only slightly stronger than that over land. Both the MCS and nonMCS vertical water transports are stronger over ocean (Fig. 9b), which is likely related to the moister environment over the offshore region.

Besides the total vertical transports, the MCS and non-MCS vertical mass/water/energy transport intensities are also compared in Figs. 9d-f. Here, the transport intensity is defined as the instantaneous total transport of each subregime divided by the detected instantaneous area in the subregime. Over both ocean and land, MCSs show stronger vertical transport intensities than non-MCSs. For example, over land (ocean), the upward mass transport intensity of MCSs is $~ 1.35$ (1.36) times stronger than that of non-MCSs at $10-\mathrm{km}$ altitude. The number changes to $\sim 1.80(1.95)$ at $3.5-\mathrm{km}$ altitude. These results imply that mesoscale organization of deep convection plays an important role in modulating the overturning circulation of the SASM. The vertical transports associated with the inland MCSs/non-MCSs (solid lines in Figs. 9d-f) are clearly deeper than that associated with the oceanic MCSs/non-MCSs (dashed lines in Figs. 9d-f). The mass/energy transport intensities in the middle and upper troposphere are significantly stronger over the inland region. For example, the inland MCS and non-MCS upward mass transport intensities at 8-km altitude are around 1.2 and 1.6 times stronger than their oceanic counterparts (Fig. 9d). Both the MCS and non-MCS upward mass transports show a more obvious upper-tropospheric peak over ocean (Fig. 9d). In particular, the top-heavy structure of non-MCS vertical mass transports shown in Fig. 7d is largely contributed by the oceanic non-MCSs. This is because stratiform regions contribute more to the total upper-tropospheric vertical transports over ocean than that over land (not shown here). This result is consistent with the long-term satellite observations that show that stratiform regions are more widespread over the offshore regions (Romatschke et al. 2010).

\section{Subseasonal variations}

The SASM exhibits strong subseasonal variability in the form of "active" and "break" spells of monsoon precipitation with a dominant mode on a time scale of 30-60 days (e.g., Sikka and Gadgil 1980; Yasunari 1981; Goswami and Ajayamohan 2001). In this section, the subseasonal variability of atmospheric overturning associated with different convective systems in the SASM is further studied in the context of the isentropic analysis.

Figure 10a shows the temporal evolution of the total upward mass transport summed over the WRF domain. Following 

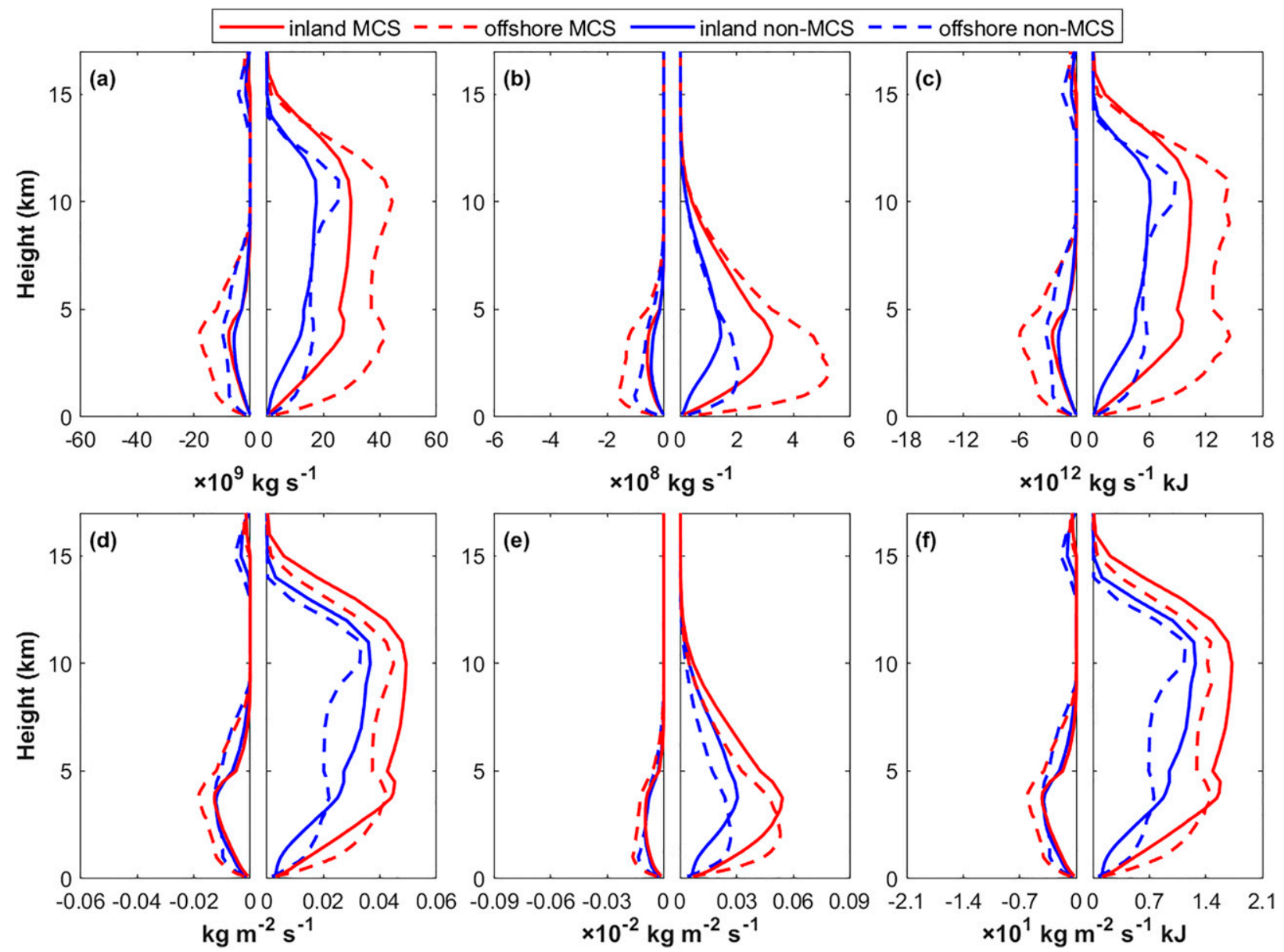

FIG. 9. (a) Vertical distributions of the downward (left side) and upward (right side) mass transports associated with inland MCS (red solid lines), offshore MCS (red dashed lines), inland non-MCS (blue solid lines), and offshore non-MCS (blue dashed lines). (b),(c) As in (a), but for vertical water and energy transports, respectively. (d)-(f) As in (a)-(c), but for the intensities of vertical mass, water, and energy transports.

Chen et al. (2018c), the monsoon active phase is defined here as days on which the total monsoonal overturning and rainfall are significantly enhanced, which occurs on 21 June-23 July and 13-29 August during JJA 2009 (shown by the black dashed lines in Fig. 10a). Days other than the active phase are defined as the monsoon break phase. The column integrated upward mass transport averaged over the active phase is around 1.22 times stronger than that during the break phase (Fig. 10a). The statistical significance of the differences in the total upward mass transports for the active and break phases is tested using Student's $t$ test. Results show that the increase in upward mass transport during the active phase is statistically significant at the $99 \%$ confidence level. During the active phase, the column integrated upward mass transport is enhanced by $\sim 24 \%$ for both MCS (Fig. 10b) and non-MCS (Fig. 10c). The convective component accounts for a relatively larger fraction of upward mass transport in MCS than that in non-MCS deep convection during both the active and break phases. The highest altitude at which the convective updraft still accounting for more than half of the upward mass transport is $9.5 \mathrm{~km}$ in the
MCS subregime (Fig. 10b) and $8 \mathrm{~km}$ in the non-MCS deep convection subregime (Fig. 10c). Congestus contributes about $31 \%$ of the total upward mass transport below the melting level (Fig. 10d). During the active phase, the column integrated upward mass transport associated with congestus is enhanced by $\sim 22 \%$. Shallow convection contributes around $26 \%$ of the total upward mass transport below $3 \mathrm{~km}$ (Fig. 10e). The column integrated upward mass transport of shallow convection is only enhanced by $\sim 8 \%$ during the monsoon active phase (Fig. 10e).

The upward energy transport in the SASM shows similar subseasonal variations as the upward mass transport (not shown here). Figure 11 shows the temporal evolutions of the upward water transports during the SASM. The column integrated total upward water transport is enhanced by $\sim 17 \%$ during the active phase (Fig. 11a). MCS contributes $41 \%$ of the column integrated total upward water transport during the SASM (Fig. 11b). Specifically, MCS accounts for around 38\% $(59 \%)$ of the total upward water transport below (above) the melting level $(\sim 6 \mathrm{~km})$. During the active phase, the column integrated upward water transport associated with MCS is 


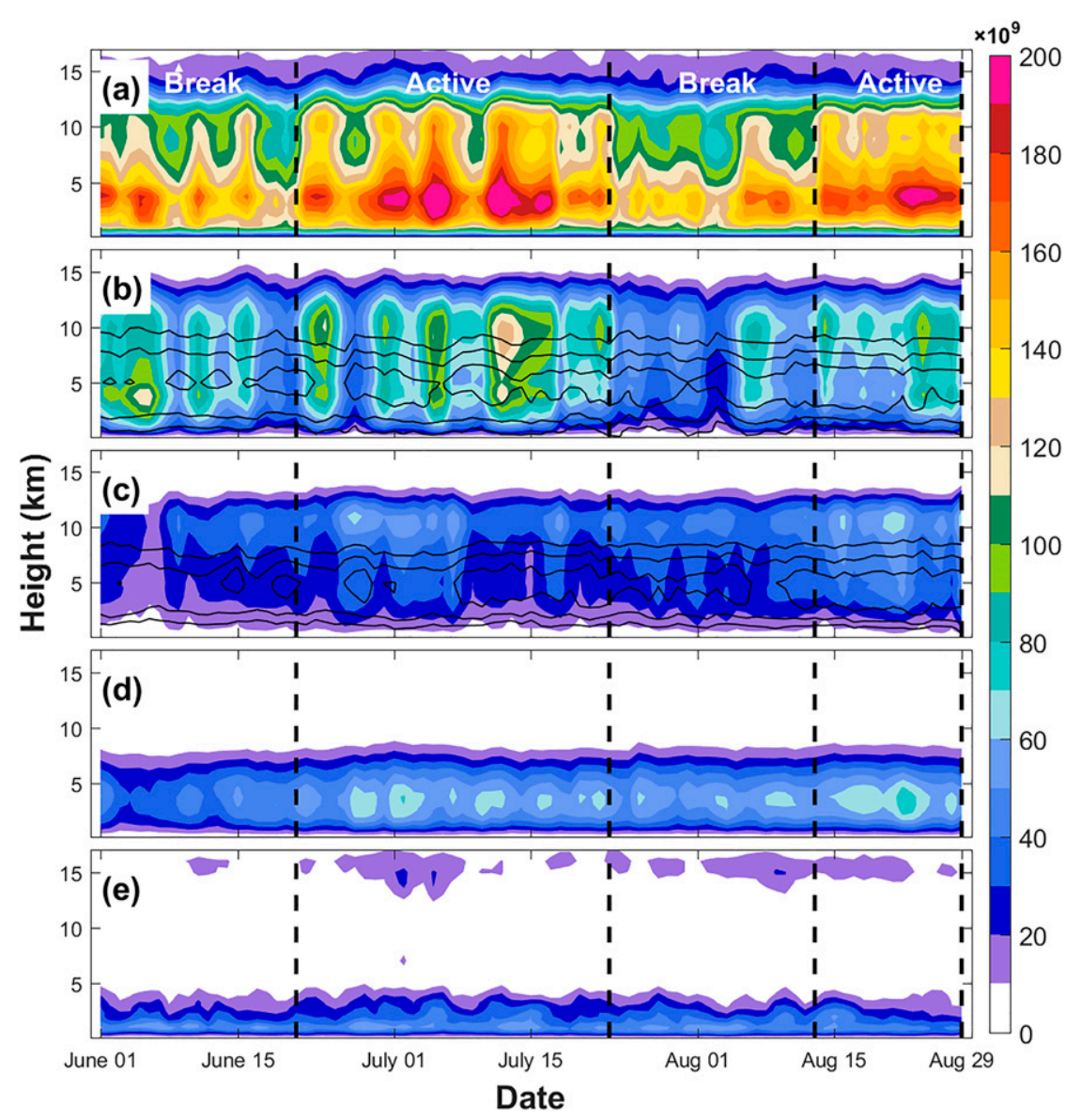

FIG. 10. Evolution of isentropic total upward mass transports (color shading; $\mathrm{kg} \mathrm{s}^{-1}$ ) associated with the (a) total SASM overturning, (b) MCS, (c) non-MCS deep convection, (d) congestus, and (e) shallow convection. The black dashed lines mark the beginning and end of two monsoon active phases. Black contours in (b) and (c) show the contributions of convective overturning to the upward mass transports for the MCS and non-MCS deep convection subregimes. The contours start at $50 \%$ with a $20 \%$ interval.

enhanced by $\sim 16 \%$. Non-MCS deep convection only contributes $17 \%$ of the column integrated total upward water transport (Fig. 11b), while the contribution from congestus is around 29\% (Fig. 11d). Most upward water transport produced by congestus is confined below the melting level, which is enhanced by $\sim 22 \%$ during the active phase. The upward water transport associated with shallow convection mostly exists below $3 \mathrm{~km}$ (Fig. 11e). Shallow convection contributes $\sim 13 \%$ of the column integrated total upward water transport. The upward water transport associated with shallow convection shows weak subseasonal variations and is enhanced by only $3 \%$ during the monsoon active phase.

The subseasonal variations of the per-feature mass, water, and energy transports associated with MCS and non-MCS deep convection are further compared in Fig. 12. The occurrence frequency of MCS is considerably increased during the active phase. The average number of MCSs that simultaneously exist in the WRF domain during the monsoon active (break) phase is 10.5 (6.5). Though the MCS number increases considerably in the monsoon active phase, the column integrated upward mass, water, and energy transports per MCS feature are slightly weakened by around $8 \%, 14 \%$, and $7 \%$, respectively (Figs. 12a-c). The occurrence frequency of non-MCS deep convection also increases during the active phase. The average number of non-MCS deep convections that simultaneously exist in the WRF domain during the active (break) phase is around 402.0 (274.1). However, the per-feature mass/water/energy transports associated with non-MCS deep convection show negligible subseasonal variations (Figs. 12d-f) during the SASM.

The subseasonal variations of the per-feature mass, water, and energy transports associated with MCS can be induced by changes of MCS area and/or vertical transport intensities. Cloud tracking results show that the averaged areas of MCS during the monsoon active and break phases are similar, which are around 96317 and $96287 \mathrm{~km}^{2}$, respectively. The MCS upward mass/water/energy transport intensities, on the other hand, are clearly weakened during the monsoon active phase, which leads to the subseasonal variations of the MCS perfeature vertical transports (not shown). The weakening of MCS vertical transport occurs over both land and ocean 


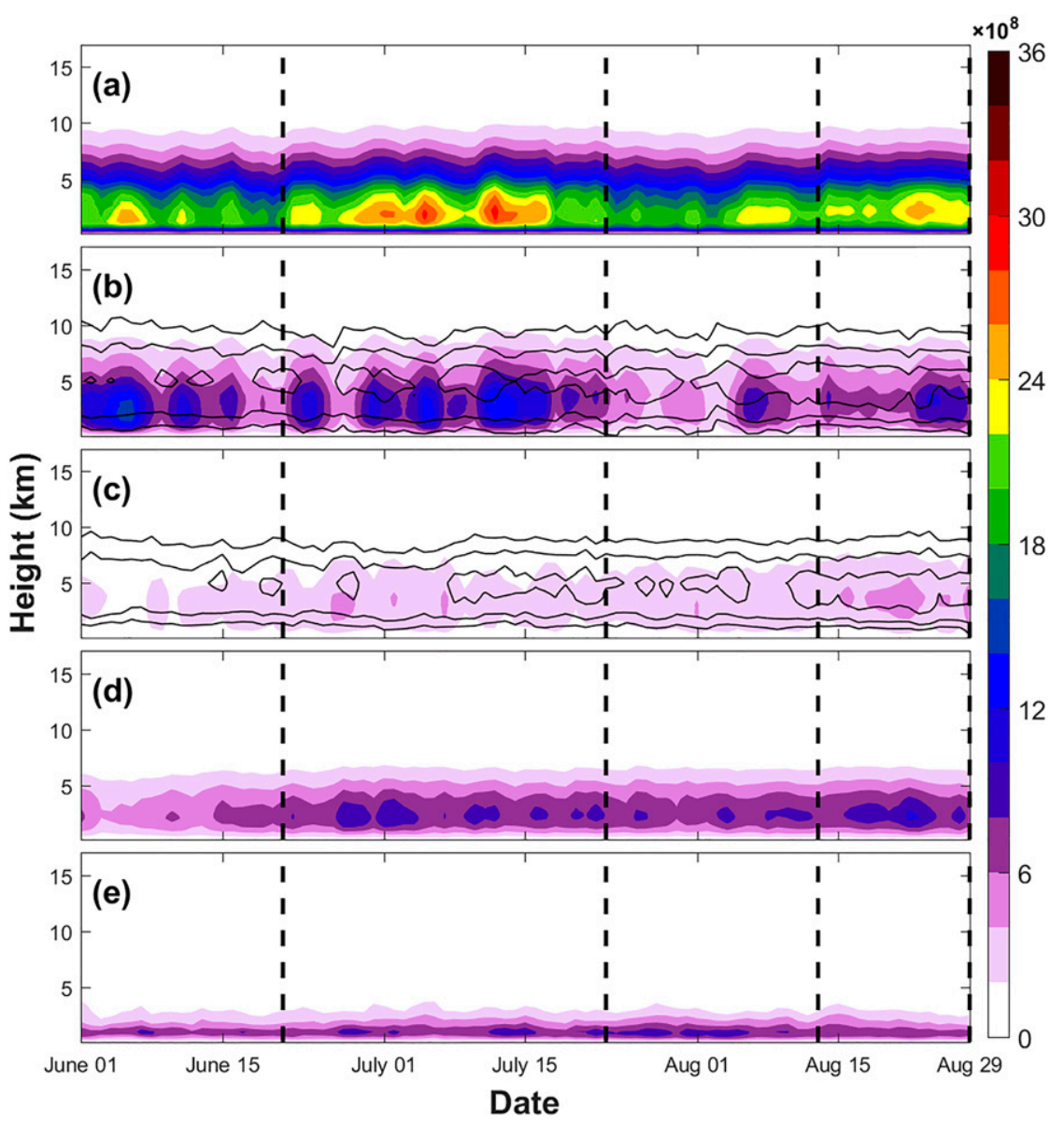

FIG. 11. As in Fig. 10, but for vertical water transports.

(Fig. 13), which is mainly caused by the reduced convective area during the active phase (not shown). The subseasonal variations of the MCS vertical transport profile reflect that MCSs during the break phase tend to have a relatively stronger MSE import effect, while MCSs during the monsoon active phase tend to have a relatively stronger MSE export effect, over both land and ocean. The subseasonal changes of the MCS overturning may be closely related to the subseasonal variations of the large-scale SASM environments, which is beyond the scope of this study but deserves future investigations. Different from MCS, neither the area nor the transport intensities of non-MCS deep convection shows clear subseasonal variation during the SASM (Fig. 13).

\section{Summary and discussion}

The vertical mass, water, and energy transports produced by convection play important roles in the SASM overturning and energetics. The SASM shows complicated convective organization morphology but our current understanding of the vertical transport characteristics of different convective systems in the SASM is still incomplete. Using a convectionpermitting regional simulation, we examine the roles of different convective systems in the vertical mass, water, and energy transports during the SASM. A cloud classification and tracking technique is used to separate the regional simulation into the MCS, non-MCS deep convection, congestus, and shallow convection plus clear-sky (shallow + clear) subregimes. Comparison with satellite observations show that the convection-permitting simulation is a more useful dataset than global reanalyses such as ERA5 for the purpose of this study, primarily because the model simulated MCS population and associated precipitation characteristics are more realistic than those from the ERA5 compared to observations. An isentropic analysis technique is used to quantify the vertical mass/water/energy transports associated with different convective systems. The isentropic analyses of vertical mass transports realistically capture the overturning structures over different convective subregimes. The two-stream approximation analysis shows that MCS plays a crucial role in the monsoonal vertical mass/water/energy transports.

The WRF simulation shows that MCS and congestus contribute the most and comparably to the upward mass/water/energy transports below the melting level. Above the melting level, the MCS overturning becomes much more dominant, which contributes around $2 / 3$ of the total upward mass and energy transports. However, the contributing percentage from 

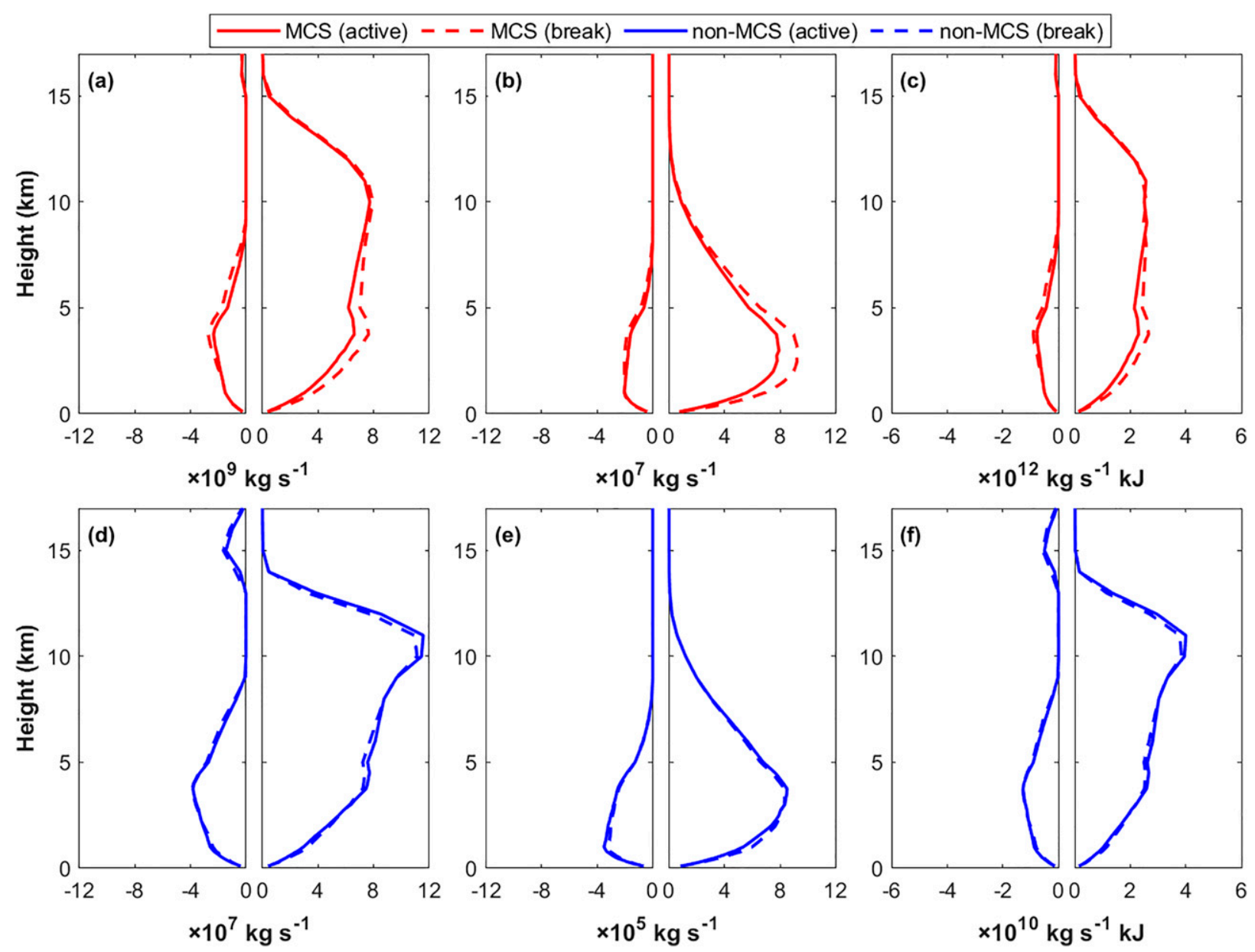

FIG. 12. (a) Vertical distributions of per-feature downward (left side) and upward (right side) mass transports associated with MCS. The solid line shows the mass transport during the active phase. The dashed line shows the mass transport during the break phase. (d) As in (a), but for non-MCS deep convection. (b),(e) As in (a) and (d), but for vertical water transport. (c),(f) As in (a) and (d), but for vertical energy transport.

congestus is very likely to be overestimated since WRF overproduces the total precipitation of congestus by a factor of 2.6.

In addition, MCS shows much stronger per-feature vertical transports than non-MCS deep convection. The per-feature upward mass/water/energy transports associated with MCS is around 70-100 times stronger than that associated with nonMCS deep convection. MCS also shows a different vertical mass/energy transport structure compared to non-MCS deep convection, with MCS upward mass/energy transports showing larger convective fractions and are broadly peaked throughout the troposphere while the non-MCS deep convection upward mass/energy transport is more dominated by stratiform overturning with a prominent top-heavy structure. Both the MCS and non-MCS deep convection lead to net MSE exports during the SASM. Per convection feature, the net MSE export by MCS is 58 times stronger than that of non-MCS deep convection. Both MCS and non-MCS vertical mass transports show more obvious top-heavy structures over ocean than that over land. Such top-heavy structures may also be expected over other tropical ocean regions, where stratiform rainfall frequently occurs due to the warm, moist boundary layer and/or the near-moist adiabatic stratification of the free atmosphere (Schumacher and Houze 2003b). In addition, the MCS vertical mass/water/energy transport intensities are significantly stronger than that of non-MCS over both land and ocean. This implies that mesoscale organization of deep convection may play an important role in modulating the SASM overturning and energetics.

The subseasonal variations of the vertical mass/water/energy transports associated with different SASM convective systems are also studied. Results show that the column integrated upward mass/water/energy transports associated with MCS, non-MCS deep convection, and congestus are enhanced by $15 \%-25 \%$ during the monsoon active phase. In contrast, the subseasonal variation of the shallow convection overturning is negligible. The per-feature vertical transports associated with MCS show a stronger subseasonal variability than that of nonMCS deep convection, which is explained by the changes of the MCS convective intensity. The vertical mass/water/energy 

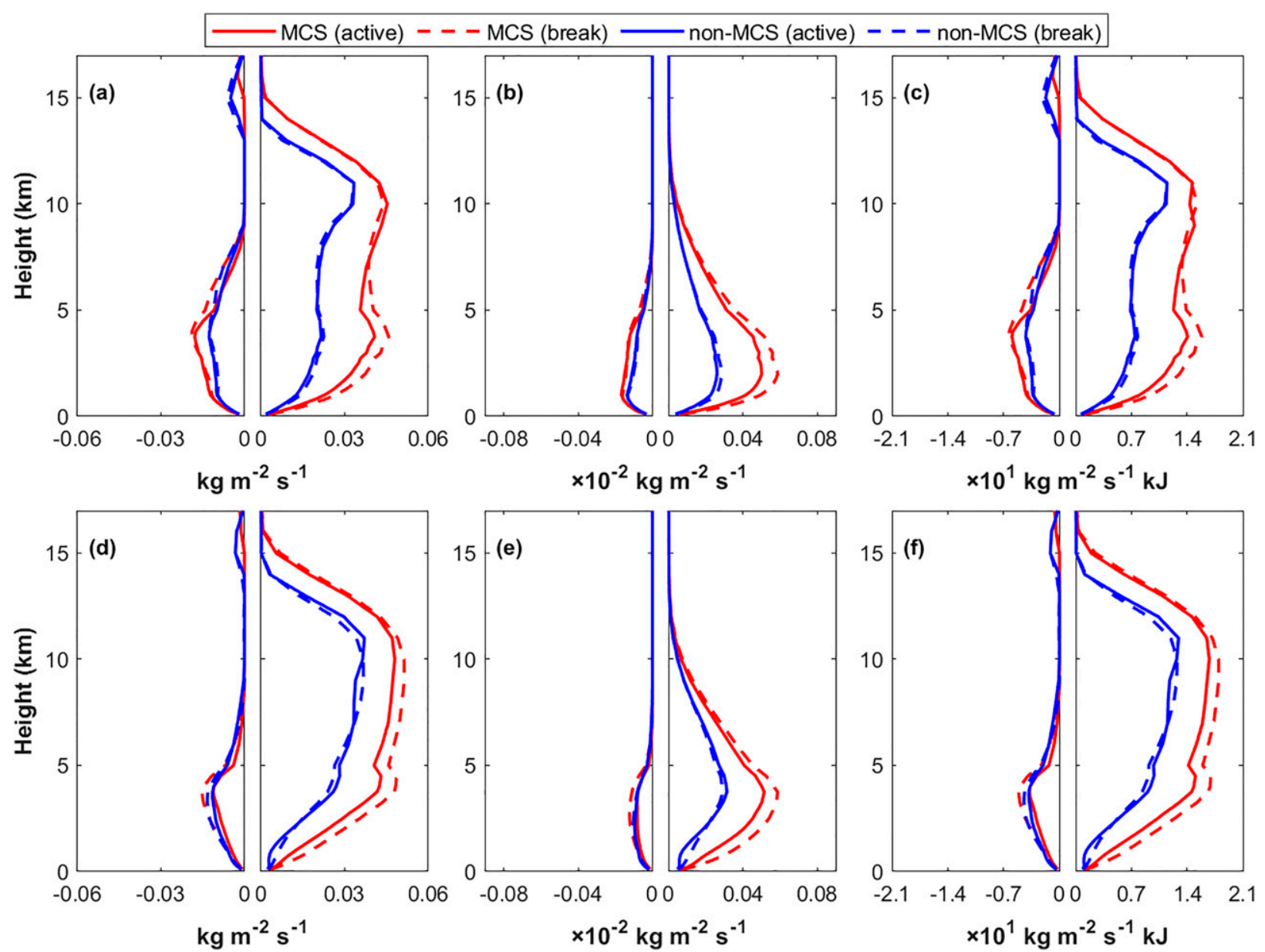

FIG. 13. (a) Vertical distributions of the downward (left side) and upward (right side) mass transport intensities associated with inland MCS (red lines) and non-MCS deep convection (blue lines). The solid line shows the active phase. The dashed line shows the break phase. (b), (c) As in (a), but for vertical water and energy transport intensities, respectively. (d)-(f) As in (a)-(c), but for offshore MCS and nonMCS deep convection.

transport intensities of MCS become weaker during the monsoon active phase compared to that in the monsoon break phase. The detailed mechanisms still deserve future studies.

Although the regional convection-permitting WRF simulation better captures the SASM convective systems than ERA5, it considerably overestimates the precipitation amount of congestus ( $\sim 2.6$ times) and slightly underestimates the precipitation amount of MCS ( $\sim 83 \%$ of the observed value). Because surface precipitation is closely related to the latent heating strengths, the current results may have underestimated the contributions from MCS and overestimated the contributions from congestus, with the potential of MCS playing an even more important role in the SASM vertical mass/water/energy transports than depicted here. In addition, the model grid spacing $(4.5 \mathrm{~km})$ used in this study is not fine enough to realistically resolve the vertical circulations associated with congestus and shallow convection. The resolution is also inadequate to resolve small non-MCS deep convection. Model biases could be expected for the results related to these subregimes. For example, the prominent top-heavy structure of the non-MCS vertical mass/energy transports may also be partially influenced by the model biases (Johnson 1984) and/or nonadjacent stratiform from MCSs. A better dataset is needed to further quantify the roles of different convective systems in the SASM overturning and the MSE import/export. Recent studies have shown that using advanced data assimilation techniques to integrate satellite observed all-sky radiances into high-resolution simulations can yield an improved analysis for tropical/monsoonal convection (e.g., Chan et al. 2020a,b), which should be considered in future studies. Multiseasonal simulations should also be considered in the future in order to investigate the impacts of interannual variability on the convection type contributions. As the first step to understand the roles of different convective systems in the SASM energy cycle, this study investigates the vertical transports associated with different convective systems. Future studies investigating the monsoon energetics from a moist entropy budget view may further advance our understanding of the roles of deep convection in the SASM and its subseasonal variability. We find different vertical transport structures and intensities of MCSs 
and non-MCSs in this study. This suggests that positive convection-wind-evaporation and cloud-radiative feedbacks as well as moist static energy exports may be significantly different for different deep convection types.

Climate models relying on cumulus parameterizations to represent deep convection often fail to simulate MCS (e.g., Van Weverberg et al. 2018; Feng et al. 2021a). Given the significant differences between the per-feature magnitude and structure of vertical transports of mass, energy, and moisture, and net MSE export between MCS and non-MCS convective systems, climate models that fail to simulate MCS may inherently have limited skill in modeling the SASM, its role in the global energy and water cycles, and its response to different forcings. The vertical transports by different convective systems quantified in this study may provide important benchmarks for evaluating and diagnosing errors in the SASM overturning simulated by climate models, understanding the implications to model projections of future SASM change, and guiding model development for future improvements.

Acknowledgments. This study is supported by the Office of Science of the U.S. Department of Energy Biological and Environmental Research as part of the Regional and Global Model Analysis program area. The WRF simulations were mainly carried out using the computing resources at the National Energy Research Scientific Computing Center (NERSC), a U.S. Department of Energy Office of Science User Facility located at Lawrence Berkeley National Laboratory, operated under Contract DE-AC02-05CH11231. Analyses of the model output were partially carried out with the computing resources at the Texas Advanced Computing Center (TACC). PNNL is operated for the Department of Energy by Battelle Memorial Institute under Contract DE-AC05-76RL01830.

\section{REFERENCES}

Ahmed, F., C. Schumacher, Z. Feng, and S. Hagos, 2016: A retrieval of tropical latent heating using the 3D structure of precipitation features. J. Appl. Meteor. Climatol., 55, 19651982, https://doi.org/10.1175/JAMC-D-15-0038.1.

Back, L. E., and C. S. Bretherton, 2006: Geographic variability in the export of moist static energy and vertical motion profiles in the tropical pacific. Geophys. Res. Lett., 33, L17810, https:// doi.org/10.1029/2006GL026672.

Bhat, G. S., and S. Kumar, 2015: Vertical structure of cumulonimbus towers and intense convective clouds over the South Asian region during the summer monsoon season. J. Geophys. Res. Atmos., 120, 1710-1722, https://doi.org/10.1002/2014JD022552.

Biasutti, M., and Coauthors, 2018: Global energetics and local physics as drivers of past, present and future monsoons. Nat. Geosci., 11, 392-400, https://doi.org/10.1038/s41561018-0137-1.

Boos, W. R., 2015: A review of recent progress on Tibet's role in the South Asian monsoon. CLIVAR Exchanges, No. 19, International CLIVAR Project Office, Southampton, United Kingdom, 23-27.

— , and Z. Kuang, 2010: Dominant control of the South Asian monsoon by orographic insulation versus plateau heating. Nature, 463, 218-222, https://doi.org/10.1038/nature08707.

Chan, M.-Y., J. L. Anderson, and X. Chen, 2020a: An efficient bi-Gaussian ensemble Kalman filter for satellite infrared radiance data assimilation. Mon. Wea. Rev., 148, 50875104, https://doi.org/10.1175/MWR-D-20-0142.1.

_, F. Zhang, X. Chen, and L. R. Leung, 2020b: Potential impacts of assimilating all-sky satellite infrared radiances on convectionpermitting analysis and prediction of tropical convection. Mon. Wea. Rev., 148, 3203-3224, https://doi.org/10.1175/MWR-D19-0343.1.

Chen, F., and J. Dudhia, 2001: Coupling an advanced land surfacehydrology model with the Penn State-NCAR MM5 modeling system. Part I: Model implementation and sensitivity. Mon. Wea. Rev., 129, 569-585, https://doi.org/10.1175/1520-0493(2001) $129<0569$ :CAALSH $>2.0 . \mathrm{CO} ; 2$.

Chen, X., and F. Zhang, 2019a: Relative roles of preconditioning moistening and global circumnavigating mode on the MJO convective initiation during DYNAMO. Geophys. Res. Lett., 46, 1079-1087, https://doi.org/10.1029/2018GL080987.

_, and _ 2019b: Development of a convection-permitting air-sea-coupled ensemble data assimilation system for tropical cyclone prediction. J. Adv. Model. Earth Syst., 11, 3474-3496, https://doi.org/10.1029/2019MS001795.

_ O. M. Pauluis, and F. Zhang, 2018a: Regional simulation of Indian summer monsoon intraseasonal oscillations at grayzone resolution. Atmos. Chem. Phys., 18, 1003-1022, https:// doi.org/10.5194/acp-18-1003-2018.

$\_$, - and $\_, 2018 \mathrm{~b}$ : Atmospheric overturning across multiple scales of an MJO event during the CINDY/DYNAMO campaign. J. Atmos. Sci., 75, 381-399, https://doi.org/10.1175/ JAS-D-17-0060.1.

,,-- L. R. Leung, and F. Zhang, 2018c: Multiscale atmospheric overturning of the Indian summer monsoon as seen through isentropic analysis. J. Atmos. Sci., 75, 3011-3030, https://doi.org/10.1175/JAS-D-18-0068.1.

,,--- , and,- 2020 : Significant contribution of mesoscale overturning to tropical mass and energy transport revealed by the ERA5 reanalysis. Geophys. Res. Lett., 47, e2019GL085333, https://doi.org/10.1029/2019GL085333.

_ - R. G. Nystrom, C. A. Davis, and C. Zarzycki, 2021: Dynamical structures of cross-domain forecast error covariance of a simulated tropical cyclone in a convection-permitting coupled atmosphere-ocean model. Mon. Wea. Rev., 149, 41-63, https:// doi.org/10.1175/MWR-D-20-0116.1.

Emanuel, K. A., 1994: Atmospheric Convection. Oxford University Press, 580 pp.

_ J. David Neelin, and C. S. Bretherton, 1994: On large-scale circulations in convecting atmospheres. Quart. J. Roy. Meteor. Soc., 120, 1111-1143, https://doi.org/10.1002/qj.49712051902.

Fan, J., and Coauthors, 2017: Cloud-resolving model intercomparison of an MC3E squall line case: Part I-Convective updrafts. J. Geophys. Res. Atmos., 122, 9351-9378, https:// doi.org/10.1002/2017JD026622.

Fang, J., O. Pauluis, and F. Zhang, 2017: Isentropic analysis on the intensification of Hurricane Edouard (2014). J. Atmos. Sci., 74, 4177-4197, https://doi.org/10.1175/JAS-D-17-0092.1.

Feng, Z., L. R. Leung, S. Hagos, R. A. Houze, C. D. Burleyson, and K. Balaguru, 2016: More frequent intense and long-lived storms dominate the springtime trend in central US rainfall. Nat. Commun., 7, 13429, https://doi.org/10.1038/ncomms13429. ,,- R. A. Houze Jr., S. Hagos, J. Hardin, Q. Yang, B. Han, and J. Fan, 2018: Structure and evolution of mesoscale convective systems: Sensitivity to cloud microphysics in convection-permitting simulations over the United States. J. Adv. Model. Earth Syst., 10, 1470-1494, https://doi.org/ 10.1029/2018MS001305. 
R. A. Houze Jr., L. R. Leung, F. Song, J. C. Hardin, J. Wang, W. I. Gustafson Jr., and C. R. Homeyer, 2019: Spatiotemporal characteristics and large-scale environments of mesoscale convective systems east of the Rocky Mountains. J. Climate, 32, 7303-7328, https://doi.org/10.1175/JCLI-D-19-0137.1.

— - F. Song, K. Sakaguchi, and L. R. Leung, 2021a: Evaluation of mesoscale convective systems in climate simulations: Methodological development and results from MPAS-CAM over the United States. J. Climate, 34, 2611-2633, https:// doi.org/10.1175/JCLI-D-20-0136.1.

—, L. R. Leung, N. Liu, J. Wang, R. A. Houze Jr., and J. Li, 2021b: A global high-resolution mesoscale convective system database using satellite-derived cloud tops, surface precipitation, and tracking. J. Geophys. Res. Atmos., 126, e2020JD034202, https://doi.org/10.1029/2020JD034202.

Goswami, B. N., and R. S. Ajayamohan, 2001: Intraseasonal oscillations and interannual variability of the Indian summer monsoon. J. Climate, 14, 1180-1198, https://doi.org/10.1175/ 1520-0442(2001)014<1180:IOAIVO > 2.0.CO;2.

Guo, Z., T. Zhou, M. Wang, and Y. Qian, 2015: Impact of cloud radiative heating on East Asian summer monsoon circulation. Environ. Res. Lett., 10, 074014, https://doi.org/10.1088/17489326/10/7/074014.

Hagos, S., Z. Feng, C. D. Burleyson, K. S. S. Lim, C. N. Long, D. Wu, and G. Thompson, 2014: Evaluation of convectionpermitting model simulations of cloud populations associated with the Madden-Julian oscillation using data collected during the AMIE/DYNAMO field campaign. J. Geophys. Res. Atmos., 119, 12 052-12 068, https://doi.org/10.1002/2014JD022143.

Han, B., and Coauthors, 2019: Cloud-resolving model intercomparison of an MC3E squall line case: Part II. Stratiform precipitation properties. J. Geophys. Res. Atmos., 124, 1090-1117, https://doi.org/10.1029/2018JD029596.

Hoffmann, L., and Coauthors, 2019: From ERA-Interim to ERA5: The considerable impact of ECMWF's next-generation reanalysis on Lagrangian transport simulations. Atmos. Chem. Phys., 19, 3097-3124, https://doi.org/10.5194/acp-193097-2019.

Houze, R. A., Jr., 2004: Mesoscale convective systems. Rev. Geophys., 42, RG4003, https://doi.org/10.1029/2004RG000150.

—, K. L. Rasmussen, M. D. Zuluaga, and S. R. Brodzik, 2015: The variable nature of convection in the tropics and subtropics: A legacy of 16 years of the Tropical Rainfall Measuring Mission satellite. Rev. Geophys., 53, 994-1021, https://doi.org/10.1002/ 2015RG000488.

Hu, H., L. R. Leung, and Z. Feng, 2020: Observed warm-season characteristics of MCS and non-MCS rainfall and their recent changes in the central United States. Geophys. Res. Lett., 47, e2019GL086783, https://doi.org/10.1029/2019GL086783.

Huffman, G., E. Stocker, D. Bolvin, E. Nelkin, and J. Tan, 2019: GPM IMERG final precipitation 13 half hourly 0.1 degree $\times$ 0.1 degree V06. NASA Goddard Earth Science Data and Information Services Center, accessed 1 June 2020, https:// doi.org/10.5067/GPM/IMERG/3B-HH/06.

Iacono, M. J., J. S. Delamere, E. J. Mlawer, M. W. Shephard, S. A. Clough, and W. D. Collins, 2008: Radiative forcing by longlived greenhouse gases: Calculations with the AER radiative transfer models. J. Geophys. Res., 113, D13103, https://doi.org/ 10.1029/2008JD009944.

Inoue, K., and L. E. Back, 2015: Gross moist stability assessment during TOGA COARE: Various interpretations of gross moist stability. J. Atmos. Sci., 72, 4148-4166, https://doi.org/10.1175/ JAS-D-15-0092.1.
Janowiak, J., B. Joyce, and P. Xie, 2017: NCEP/CPC L3 half hourly $4 \mathrm{~km}$ global $(60 \mathrm{~S}-60 \mathrm{~N})$ merged IR V1. NASA Goddard Earth Science Data and Information Services Center, accessed 1 June 2020, https://doi.org/10.5067/P4HZB9N27EKU.

Johnson, R. H., 1984: Partitioning tropical heat and moisture budgets into cumulus and mesoscale components: Implications for cumulus parameterization. Mon. Wea. Rev., 112, 1590-1601, https://doi.org/10.1175/1520-0493(1984)112<1590:PTHAMB> 2.0.CO;2.

— T. M. Rickenbach, S. A. Rutledge, P. E. Ciesielski, and W. H. Schubert, 1999: Trimodal characteristics of tropical convection. J. Climate, 12, 2397-2418, https://doi.org/10.1175/15200442(1999)012<2397:TCOTC>2.0.CO;2.

Kumar, S., and G. Bhat, 2017: Vertical structure of orographic precipitating clouds observed over South Asia during summer monsoon season. J. Earth Syst. Sci., 126, 114, https://doi.org/ 10.1007/s12040-017-0897-9.

Lim, K.-S. S., and S.-Y. Hong, 2010: Development of an effective double-moment cloud microphysics scheme with prognostic cloud condensation nuclei $(\mathrm{CCN})$ for weather and climate models. Mon. Wea. Rev., 138, 1587-1612, https://doi.org/ 10.1175/2009MWR2968.1.

Luo, Z., and G. L. Stephens, 2006: An enhanced convectionwind-evaporation feedback in a superparameterization GCM (SP-GCM) depiction of the Asian summer monsoon. Geophys. Res. Lett., 33, L06707, https://doi.org/10.1029/ 2005 GL025060.

Ma, D., A. H. Sobel, Z. Kuang, M. S. Singh, and J. Nie, 2019: A moist entropy budget view of the South Asian summer monsoon onset. Geophys. Res. Lett., 46, 4476-4484, https://doi.org/ 10.1029/2019GL082089.

Mohr, K. I., J. S. Famiglietti, and E. J. Zipser, 1999: The contribution to tropical rainfall with respect to convective system type, size, and intensity estimated from the $85-\mathrm{GHz}$ ice-scattering signature. J. Appl. Meteor., 38, 596-606, https://doi.org/10.1175/15200450(1999)038<0596:TCTTRW > 2.0.CO;2.

Mrowiec, A. A., O. M. Pauluis, A. M. Fridlind, and A. S. Ackerman, 2015: Properties of a mesoscale convective system in the context of an isentropic analysis. J. Atmos. Sci., 72, 1945-1962, https://doi.org/10.1175/JAS-D-14-0139.1.

,-- , and F. Zhang, 2016: Isentropic analysis of a simulated hurricane. J. Atmos. Sci., 73, 1857-1870, https://doi.org/10.1175/ JAS-D-15-0063.1.

Neelin, J. D., and I. M. Held, 1987: Modeling tropical convergence based on the moist static energy budget. Mon. Wea. Rev., 115, 3-12, https://doi.org/10.1175/1520-0493(1987)115<0003: MTCBOT>2.0.CO;2.

Nie, J., W. R. Boos, and Z. Kuang, 2010: Observational evaluation of a convective quasi-equilibrium view of monsoons. J. Climate, 23, 4416-4428, https://doi.org/10.1175/2010JCLI3505.1.

Pauluis, O. M., 2016: The mean air flow as Lagrangian dynamics approximation and its application to moist convection. J. Atmos. Sci., 73, 4407-4425, https://doi.org/10.1175/JAS-D-15-0284.1.

$\longrightarrow$, and A. A. Mrowiec, 2013: Isentropic analysis of convective motions. J. Atmos. Sci., 70, 3673-3688, https://doi.org/10.1175/ JAS-D-12-0205.1.

— A. Czaja, and R. Korty, 2008: The global atmospheric circulation on moist isentropes. Science, 321, 1075-1078, https:// doi.org/10.1126/science.1159649.

Pleim, J. E., 2007: A combined local and nonlocal closure model for the atmospheric boundary layer. Part I: Model description and testing. J. Appl. Meteor. Climatol., 46, 1383-1395, https:// doi.org/10.1175/JAM2539.1. 
Prakash, S., M. R. Ramesh Kumar, S. Mathew, and R. Venkatesan, 2018: How accurate are satellite estimates of precipitation over the north Indian Ocean? Theor. Appl. Climatol., 134, 467-475, https://doi.org/10.1007/s00704-017-2287-2.

Prein, A., R. Rasmussen, D. Wang, and S. Giangrande, 2021: Sensitivity of organized convective storms to model grid spacing in current and future climates. Philos. Trans. Roy. Soc., A379, 20190546, https://doi.org/10.1098/rsta.2019.0546.

Raymond, D. J., S. L. Sessions, A. H. Sobel, and Ž. Fuchs, 2009: The mechanics of gross moist stability. J. Adv. Model. Earth Syst., 1, 9, https://doi.org/10.3894/JAMES.2009.1.9.

Romatschke, U., and R. A. Houze, 2011: Characteristics of precipitating convective systems in the South Asian monsoon. J. Hydrometeor., 12, 3-26, https://doi.org/10.1175/2010JHM1289.1.

__, S. Medina, and R. A. Houze Jr., 2010: Regional, seasonal, and diurnal variations of extreme convection in the South Asian region. J. Climate, 23, 419-439, https://doi.org/10.1175/ 2009JCLI3140.1.

Sabin, T. P., and O. M. Pauluis, 2020: The South Asian monsoon circulation in moist isentropic coordinates. J. Climate, 33, 5253-5270, https://doi.org/10.1175/JCLI-D-19-0637.1.

Saikranthi, K., T. Narayana Rao, B. Radhakrishna, and S. V. B. Rao, 2014: Morphology of the vertical structure of precipitation over India and adjoining oceans based on long-term measurements of TRMM PR. J. Geophys. Res. Atmos., 119, 8433-8449, https://doi.org/10.1002/2014JD021774.

Schumacher, C., and R. A. Houze, 2003a: The TRMM precipitation radar's view of shallow, isolated rain. J. Appl. Meteor., 42, 1519-1524, https://doi.org/10.1175/1520-0450(2003)042<1519: TTPRVO $>2.0 . \mathrm{CO} ; 2$.

— and - 2003b: Stratiform rain in the tropics as seen by the TRMM precipitation radar. J. Climate, 16, 1739-1756, https:// doi.org/10.1175/1520-0442(2003)016<1739:SRITTA >2.0.CO;2.

—, S. N. Stevenson, and C. R. Williams, 2015: Vertical motions of the tropical convective cloud spectrum over Darwin, Australia. Quart. J. Roy. Meteor. Soc., 141, 2277-2288, https://doi.org/ 10.1002/qj.2520.

Senior, C. A., and Coauthors, 2021: Convection permitting regional climate change simulations for understanding future climate and informing decision making in Africa. Bull. Amer. Meteor. Soc., 102, E1206-E1223, https://doi.org/10.1175/BAMS-D-200020.1

Shi, J. J., and Coauthors, 2010: WRF simulations of the 2022 January 2007 snow events over eastern Canada: Comparison with in situ and satellite observations. J. Appl. Meteor. Climatol., 49, 2246-2266, https://doi.org/10.1175/2010JAMC2282.1.

Sikka, D. R., and S. Gadgil, 1980: On the maximum cloud zone and the ITCZ over Indian longitudes during the southwest monsoon. Mon. Wea. Rev., 108, 1840-1853, https://doi.org/10.1175/ 1520-0493(1980)108<1840:OTMCZA > 2.0.CO;2.

Skamarock, W., and Coauthors, 2008: A description of the Advanced Research WRF version 3. NCAR Tech. Note NCAR/TN475+STR, 113 pp., https://doi.org/10.5065/D68S4MVH.

Slawinska, J., O. Pauluis, A. J. Majda, and W. W. Grabowski, 2016: Multiscale interactions in an idealized Walker cell: Analysis with isentropic streamfunctions. J. Atmos. Sci., 73, 1187-1203, https://doi.org/10.1175/JAS-D-15-0070.1.

Song, F., Z. Feng, L. R. Leung, R. A. Houze Jr., J. Wang, J. Hardin, and C. R. Homeyer, 2019: Contrasting spring and summer large-scale environments associated with mesoscale convective systems over the U.S. Great Plains. J. Climate, 32, 6749-6767, https://doi.org/10.1175/JCLI-D-18-0839.1.

Thompson, G., P. R. Field, R. M. Rasmussen, and W. D. Hall, 2008: Explicit forecasts of winter precipitation using an improved bulk microphysics scheme. Part II: Implementation of a new snow parameterization. Mon. Wea. Rev., 136, 5095-5115, https://doi.org/10.1175/2008MWR2387.1.

Tokay, A., and D. A. Short, 1996: Evidence from tropical raindrop spectra of the origin of rain from stratiform versus convective clouds. J. Appl. Meteor., 35, 355-371, https://doi.org/10.1175/ 1520-0450(1996)035<0355:EFTRSO > 2.0.CO;2.

Trenberth, K. E., D. P. Stepaniak, and J. M. Caron, 2000: The global monsoon as seen through the divergent atmospheric circulation. J. Climate, 13, 3969-3993, https://doi.org/10.1175/ 1520-0442(2000)013<3969:TGMAST>2.0.CO;2.

Van Weverberg, K., and Coauthors, 2018: Causes: Attribution of surface radiation biases in NWP and climate models near the U.S. southern Great Plains. J. Geophys. Res. Atmos., 123, 3612-3644, https://doi.org/10.1002/2017JD027188.

Varble, A., and Coauthors, 2014: Evaluation of cloud-resolving and limited area model intercomparison simulations using TWP-ICE observations: 1. Deep convective updraft properties. J. Geophys. Res. Atmos., 119, 13 891-13918, https:// doi.org/10.1002/2013JD021371.

Virts, K. S., and R. A. Houze, 2016: Seasonal and intraseasonal variability of mesoscale convective systems over the South Asian monsoon region. J. Atmos. Sci., 73, 4753-4774, https:// doi.org/10.1175/JAS-D-16-0022.1.

Wall, C., C. Liu, and E. Zipser, 2013: A climatology of tropical congestus using CloudSat. J. Geophys. Res. Atmos., 118, 64786492, https://doi.org/10.1002/jgrd.50455.

Wang, P. X., B. Wang, H. Cheng, J. Fasullo, Z. Guo, T. Kiefer, and Z. Liu, 2017: The global monsoon across time scales: Mechanisms and outstanding issues. Earth-Sci. Rev., 174, 84-121, https:// doi.org/10.1016/j.earscirev.2017.07.006.

Wang, S., A. H. Sobel, F. Zhang, Y. Q. Sun, Y. Yue, and L. Zhou, 2015: Regional simulation of the October and November MJO events observed during the CINDY/DYNAMO field campaign at gray zone resolution. J. Climate, 28, 2097-2119, https://doi.org/10.1175/JCLI-D-14-00294.1.

Wu, Y., J. Lu, and O. Pauluis, 2019: Weakening of upward mass but intensification of upward energy transport in a warming climate. Geophys. Res. Lett., 46, 1672-1680, https://doi.org/ 10.1029/2018GL081399.

Xu, W., and E. J. Zipser, 2012: Properties of deep convection in tropical continental, monsoon, and oceanic rainfall regimes. Geophys. Res. Lett., 39, L07802, https://doi.org/10.1029/2012GL051242.

Yanai, M., S. Esbensen, and J.-H. Chu, 1973: Determination of bulk properties of tropical cloud clusters from large-scale heat and moisture budgets. J. Atmos. Sci., 30, 611-627, https://doi.org/ 10.1175/1520-0469(1973)030<0611:DOBPOT $>2.0 . C O ; 2$.

Yang, G.-Y., and J. Slingo, 2001: The diurnal cycle in the tropics. Mon. Wea. Rev., 129, 784-801, https://doi.org/10.1175/15200493(2001)129<0784:TDCITT>2.0.CO;2.

Yasunari, T., 1981: Structure of an Indian summer monsoon system with around 40-day period. J. Meteor. Soc. Japan, 59, 336-354, https://doi.org/10.2151/jmsj1965.59.3_336.

Zuluaga, M. D., C. D. Hoyos, and P. J. Webster, 2010: Spatial and temporal distribution of latent heating in the South Asian monsoon region. J. Climate, 23, 2010-2029, https://doi.org/ 10.1175/2009JCLI3026.1. 